\title{
EL TRIBUNAL CONSTITUCIONAL Y EL USO DE “TESTS”: UNA METODOLOGÍA NECESARIA PARA FORTALECER LA REVISIÓN JUDICIAL ECONÓMICA
}

\author{
THE CONSTITUTIONAL COURT AND THE USE OF STANDARDS: A \\ NECESSARY METHODOLOGY FOR STRENGHTENING ECONOMIC \\ JUDICIAL REVIEW
}

\author{
JosÉ FranCisco GarCía GARCÍA* **
}

\begin{abstract}
RESUMEN: El autor sugiere que el actual uso de ciertos "tests", estándares o parámetros de control que están siendo utilizados por el Tribunal Constitucional (TC) a la hora de efectuar el control de constitucionalidad de la ley, es un gran aporte de cara a fortalecer la revisión judicial de la regulación económica. Las bondades de esta metodología de control son diversas: objetiviza el control, eleva la fundamentación y calidad de las sentencias y aumenta la certeza jurídica. Con todo, el autor propone que es posible sofisticar el uso de estos instrumentos. Para ello, el autor confronta el uso que ha hecho el TC del principio de proporcionalidad y la expropiación regulatoria, con lo que han hecho sus pares español (Tribunal Constitucional español) y norteamericano (Corte Suprema), respecto de los mismos. Plantea que es todavía posible alcanzar mayores niveles de profundidad en el uso de estos tests, si se examinan la experiencia de ambos foros del derecho comparado.
\end{abstract}

Palabras clave: Tribunal Constitucional, revisión judicial, estándares de control, principio de proporcionalidad, expropiación regulatoria, regulación económica.

ABSTRACT: The author suggests that the use of certain judicial standards by the Chilean Constitutional Court (TC) when exercising its judicial review authority is an enormous step towards strengthening the judicial review of economic regulation. The benefits of the use of this methodology are several: minimizes the space for judicial discretion, improves the quality of the decisions, and raises juridical certainty. However, the author suggests that it is possible to sophisticate the use of these standards. For achieving this, he confronts the jurisprudence that the TC has generated through the use of the proportionality principle and regulatory takings, with the jurisprudence generated by the Spanish Constitutional Court and the American Supreme Court, respectively. The author states that it is possible to raise the depth of both tests in Chile, if the TC examines the experience of its counterparts of Spain and the United States.

Key words: Constitutional Court, judicial review, standards, proportionality principle, regulatory takings, economic regulation.

\footnotetext{
* Abogado. Licenciado en Ciencias Jurídicas y Magíster en Derecho Público, Pontificia Universidad Católica de Chile. Máster (LL.M) y Doctor en Derecho (JSD), Universidad de Chicago. Profesor de Derecho Constitucional de la Pontificia Universidad Católica de Chile y de la Universidad del Desarrollo. Abogado del Estudio Jurídico Morales y Besa. Correo electrónico: jfgarcia@moralesybesa.cl.

** Agradezco los comentarios de la Profesora de Derecho de la UDD Camila Boettiger, como también a los ayudantes de la Dirección de Investigación de la Facultad de Derecho de la UDD, Paulina Lobos, Juan Pablo Schnake y Andrés Munizaga por su invaluable ayuda. Este artículo es una de las publicaciones derivadas del proyecto "La regulación económica en la jurisprudencia del Tribunal Constitucional", en el marco del concurso de Fondos de Investigación UDD 2009.
} 


\section{INTRODUCCIÓN}

Un factor relevante a la hora de buscar fortalecer la revisión judicial de la regulación económica dice relación con la profundización del uso de tests, estándares o parámetros de control por parte del TC, y en particular, ir sofisticando su utilización por parte de los jueces constitucionales ${ }^{1}$.

Así, no solo importa el fondo perseguido a través de la revisión judicial económica, que no es otra cosa que la defensa de las libertades individuales en el ámbito económico; sino además, es relevante la forma: la existencia de una metodología para el escrutinio de las mismas. Es lo que ha pasado en materia de expropiación regulatoria, como asimismo con el uso creciente del principio de proporcionalidad. Ello va en la dirección correcta. En esta materia el TC está dando pasos gigantescos, en la senda correcta, que debemos incentivar y ayudar, desde la dogmática ius publicista. Somos corresponsables de este esfuerzo.

En efecto, el uso de tests, parámetros o estándares de control judicial generan diversos beneficios sociales. En primer lugar, se trata de buscar un control más objetivo por parte de los jueces, cuestión que se consigue generando una metodología de evaluación al momento de efectuar el control. Ello potencia decisiones basadas en razonamientos jurídicos más que el uso desmedido de citas y de argumentos que no tienen conexión los unos con los otros, tan propios de nuestro sistema continental. Segundo, y estrechamente vinculado con lo anterior, ello eleva notoriamente la fundamentación y calidad de las sentencias, elemento clave a la hora de exigir accountability a jueces que no gozan de legitimidad democrática directa. Tercero, generan niveles de certeza jurídica mayores en la medida en que el legislador, ejecutivo y agencias administrativas, como también los ciudadanos, saben con claridad cómo serán evaluados sus actos ex ante. Ello contribuye, además, a disminuir los incentivos de actuaciones arbitrarias del regulador.

Nótese, además, que los tests pueden llegar a cumplir en la práctica, un rol equivalente al de los precedentes en el sistema de common law. En efecto, una aplicación continua y permanente de estos tests va obligando al juez a razonar y a seguir la metodología que ha utilizado para casos similares al momento de fundamentar una nueva sentencia. Más aún si se genera con esto un espacio para una incorporación parcial del stare decisis al Tribunal Constitucional y a la Corte Suprema, en la medida que el efecto multiplicador del uso de tests resultaría evidente ${ }^{2}$.

\footnotetext{
${ }^{1}$ Es difícil definir el concepto de test, especialmente porque el derecho norteamericano (jurisdicción que los ha masificado), a diferencia de la tradición continental, suele ser rehacia a las definiciones. A lo anterior, se suma el que se trata de doctrinas jurisprudenciales respecto de la revisión judicial, y cada caso analizado por un juez, pero en particular por la Corte Suprema Federal (dado el poder del stare decisis vertical) presenta una oportunidad para desarrollar un nuevo test o sofisticar uno anterior. Nuestra idea de test se ubica ahí donde el debate norteamericano trata de conceptualizar las nociones de "reglas", "estándares", "categorías" y "ponderación". Para adentrarse en este debate ver el magnífico artículo de SULLIVAN (1993).

${ }^{2}$ García (2009b) y García y Verdugo (2010). Ver también Zapata (2008).
} 
A lo anterior se suma el hecho que la reforma constitucional de 2005, a través de la ley No 20.050, en materia de inaplicabilidad (93 No 6 de la Constitución Política de la República, CPR), potencia el desarrollo y perfeccionamiento de tests.

En efecto, hay un contexto institucional nuevo que, a nuestro juicio, facilita avanzar en la implementación y desarrollo de los tests ${ }^{3}$. En este sentido, coincidimos con Romero en el alcance de que el control concreto vinculado a la nueva inaplicabilidad, impulsa al TC a introducirse en el análisis fáctico-empírico ${ }^{4}$, permitiéndole entregar un nuevo sentido, por ejemplo, a la evidencia empírica proporcionada por peritos, expertos (economistas), etc., cuando se está hablando de la "magnitud" o "intensidad" en materia de expropiación regulatoria. Asimismo, ello se vincula al desarrollo de la estructura procesal de la inaplicabilidad, los estándares e instrumentos probatorios, el uso de medidas para mejor resolver, entre otros. En otras palabras, el diseño institucional-procesal de la inaplicabilidad y el control concreto, creemos potencian el espacio en que los criterios económicos puedan tener cabida e iluminar de mejor forma las decisiones del sentenciador constitucional.

Bajo este contexto, el desafío de este trabajo es confrontar el uso de dos tests que están siendo utilizados por el TC como parámetros de control de constitucionalidad, a saber, el principio de proporcionalidad y el de expropiación regulatoria, con la labor de sus pares en el derecho comparado, con el objeto de encontrar algunos lineamientos para ir sofisticando el uso de estos tests por parte del TC.

Para ello analizaremos la evolución jurisprudencial que podemos observar en el Tribunal Constitucional español respecto del principio de $\operatorname{proporcionalidad}^{5}$ y de la Corte Suprema norteamericana respecto de la expropiación regulatoria. Ambas prácticas jurisprudenciales nos entregan elementos que pueden enriquecer tremendamente nuestra comprensión y uso de estos instrumentos.

Finalmente, queremos mostrar que, si bien la proporcionalidad tiene un campo de aplicación mucho más extenso -como ha dado cuenta la práctica jurisprudencial del TC-, creemos que estos dos tests, pueden convertirse -junto al principio de protección de la confianza- en los estándares más robustos y sofisticados a la hora de evaluar la constitucionalidad de diversas regulaciones económicas. Así, nos interesa prestar particular atención a la forma en que la jurisprudencia de ambas cortes internacionales, como la dogmática que la ha analizado, incorpora los elementos económicos envueltos en la revisión judicial.

\footnotetext{
${ }^{3}$ Acerca de la nueva inaplicabilidad, y sus implicancias desde la perspectiva del control concreto ver, por ejemplo, ZúNiga (2005), NOGUEIRA (2005) FERMANDOIS (2008).

${ }^{4}$ ROMERo (2008) p. 48.

5 El cual hemos seguido debido a que no manejamos el idioma alemán, dado que lo ideal es analizar la jurisprudencia del Tribunal Constitucional alemán. Ello nos parece fundamental a la hora de realizar ejercicios de derecho comparado. Las meras traducciones al español de la jurisprudencia alemana nos parecen fuente de potenciales errores relevantes que hemos querido evitar. No obstante, el Tribunal Constitucional español sigue, a su modo, al alemán, como asimismo el primero es referente indiscutido del Tribunal Constitucional chileno.
} 


\section{PROPORCIONALIDAD}

En términos generales, la proporcionalidad es definida por la RAE como la "conformidad o proporción de unas partes con el todo o de cosas relacionadas entre sí” 6 , de manera que refleja un elemento de correlación entre dos o más variables y la necesaria comparación y correspondencia entre ellas ${ }^{7}$. Su formulación en el área del derecho es relativamente reciente ${ }^{8}$, sin embargo, la noción de proporcionalidad aparece íntimamente relacionada con la idea de justicia material y, por consiguiente, ha estado presente, de un modo u otro, a lo largo de la historia del pensamiento no solo jurídico, sino moral (e.g., "el fin no justifica los medios") y filosófico?.

El principio de proporcionalidad -también denominado prohibición del exceso ${ }^{10}$ y que ha sido entendido como un mandato de optimización ${ }^{11}$, , ha sido aceptado por la doctrina nacional ${ }^{12}$ y por la jurisprudencia contemporánea del Tribunal Constitucional chileno $^{13}$. Se trata de una institución que ha sido importada desde el extranjero, especialmente del Tribunal Constitucional Alemán ${ }^{14}$ (y Español, en el caso chileno) ${ }^{15}$ 16; y de gran desarrollo en los tribunales europeos (i.e., Corte Europea de Justicia o la Corte Europea de DD.HH.), como también, sostienen algunos autores, por la Corte Suprema norteamericana en su forma de test del escrutinio estricto (strict scrutiny) ${ }^{17}$.

${ }^{6}$ Real ACAdemia de la Lengua Española (2005) p. 1846.

7 FERNÁNDEZ (2008) p. 300.

8 FERnÁNDEZ (2008) p. 277. Como veremos a continuación, si bien tiene antecedentes anteriores, su consagración como tal solo vino a hacerse presente en el siglo XIX, a través de la jurisprudencia del Tribunal Constitucional alemán.

${ }^{9}$ FERNÁNDEZ (2008) p. 277.

10 Ver, por ejemplo, KLUTH (1998) p. 219 y ss.

11 Esta es la tesis del influyente jurista alemán Robert Alexy, por la cual se impone al resolutor de un conflicto la obligación de buscar una alternativa óptima y lícita. AlEXY (2002) p. 13.

12 Entre otros, véase a NogUEIRA (2006) pp. 386-391; FERMANDOIS (2006) pp. 263-264; FERMANDOIS (2008); AldunATE (2008) pp. 264-267. A juicio de Nogueira, el principio de proporcionalidad se encuentra integrado constitucionalmente en la prohibición general de la arbitrariedad, así como en las garantías establecidas en las bases de la institucionalidad que dan forma al Estado de Derecho y en la garantía normativa del contenido esencial de los derechos, además del valor de justicia inherente al Derecho. De este modo señala que: “...el principio de proporcionalidad opera como un límite a todas las restricciones de los derechos esenciales o fundamentales, derivando su aplicación del principio del Estado de Derecho, por lo cual tiene rango constitucional. Tal derivación del Estado de Derecho, es en virtud del contenido esencial de los derechos que no pueden ser limitados más allá de lo imprescindible para la protección de los intereses públicos”. NogueIRA (1997) p. 184.

13 Por primera vez de manera explícita en Sentencia Tribunal del Constitucional, Rol No 790 (2007) c. 22.

14 Engel (2001); Fermandois (2006) pp. 169-170.

15 BARNeS (1994); SARMiEnTO (2003) p.154. Véase el fundamento 7 de la Sentencia 49/1999 del Tribunal Constitucional español, donde señala que "Desde nuestras primeras resoluciones (STC 62/1982) hasta las más recientes (especialmente, STC 55/1996 y 161/1997), hemos consagrado el principio de proporcionalidad como un principio general que puede inferirse a través de diversos preceptos constitucionales".

${ }^{16}$ Cabe hacer presente que este principio también ha entrado a la jurisprudencia constitucional de la Corte Suprema de Estados Unidos y del Tribunal de las Comunidades Europeas. SAONA (2009) p. 3.

17 En el derecho americano se han establecido tres niveles en la valoración jurídico-constitucional de las normas que podrían vulnerar garantías fundamentales, en particular, la equal protection clause o la primera enmienda, de modo que cuando el criterio de diferenciación empleado por el legislador resulte particularmente delicado se abandona el test de mera racionalidad y se incrementa el nivel de exigencia que la Corte 
De esta manera, encontramos una nueva forma de precisar los alcances de la interdicción de la arbitrariedad ${ }^{18}$ y los parámetros del denominado juicio de igualdad ${ }^{19}$.

Se trata entonces de un principio constitucional de adjudicación propio de la globalización, tanto por ser el procedimiento preferido por los jueces cuando se busca resolver las colisiones en el ejercicio de derechos, o entre una garantía constitucional y un legítimo interés estatal o público ${ }^{20}$; como también, de un movimiento doctrinario que busca empoderar a los jueces en su labor de revisión judicial, afectando el equilibrio relativo entre los poderes estatales ${ }^{21}$.

Como sostiene Barnes, representativo de la doctrina española, se entiende por proporcionalidad aquel:

"principio constitucional en virtud del cual la intervención pública ha de ser 'susceptible' de alcanzar la finalidad perseguida, 'necesaria' o imprescindible al no haber otra medida menos restrictiva de la esfera de libertad de los ciudadanos (es decir, por ser el medio más suave y moderado de entre todos los posibles -ley del mínimo intervencionismo-) y 'proporcional' en sentido estricto, es decir, 'ponderada' o equilibrada por derivarse de aquélla más beneficios o ventajas para el interés general que perjuicios sobre otros bienes, valores o bienes en conflicto, en particular sobre los derechos y libertades"22.

requiere para admitir la constitucionalidad de la norma, pasando primero por el test del escrutinio intermedio (intermediate scrutiny) y, posteriormente, al más estricto. En efecto, el llamado strict scrutiny test se utiliza cuando el criterio empleado por el legislador para fundamentar la diferencia de tratamiento es la raza o cuando puede verse afectado un derecho o interés considerado fundamental y el igual acceso a la justicia. En estos casos el legislador ha de probar la existencia de un interés extraordinario o apremiante (compelling interest) para legitimar la diferencia normativa introducida y la consiguiente limitación de valores constitucionales fundamentales y además tal diferencia de trato ha de estar estrechamente conectada (narrowly tailored) con la satisfacción de dicho interés, de modo que no exista ningún medio menos discriminatario para su consecución. En la práctica si el Tribunal Supremo se inclina por aplicar este strict scrutiny test, las posibilidades de que la norma impugnada no acabe siendo declarada inconstitucional son muy escasas. Ver MARTIN (2003); y SwEET y MATHEWS (2010).

18 Esta visión tradicional proviene de una cita recurrente al constitucionalista argentino Segundo Linares Quintana. La misma puede sintetizarse en las palabras del propio Tribunal Constitucional: "la igualdad ante la ley consiste en que las normas jurídicas deben ser iguales para todas las personas que se encuentren en las mismas circunstancias y, consecuencialmente, diversas para aquellas que se encuentren en situaciones diferentes. No se trata, por consiguiente, de una igualdad absoluta sino que ha de aplicarse la ley en cada caso conforme a las diferencias constitutivas del mismo. La igualdad supone, por lo tanto, la distinción razonable entre quienes no se encuentren en la misma condición". Por lo tanto, concluye, "la razonabilidad es el cartabón o estándar de acuerdo con el cual debe apreciarse la medida de igualdad o la desigualdad". Sentencia del Tribunal Constitucional, Rol No 790 (2007) c. 21. Véase además las Sentencias del Tribunal Constitucional Roles No 28 (1985), 53 (1988).

19 Hay que hacer presente que la proporcionalidad no solo ha sido elaborada a propósito del art. 19 No 2 de la Constitución, sino que también respecto de otros preceptos que tienen algún contenido relativo a la igualdad. Tal es el caso, por ejemplo, de FERMANDOIs (2006) pp. 263-264.

20 SWEET y MATHEWS (2008) p. 74.

21 SWEET y MATHEWS (2008) pp. 160-61.

22 BARnes (1994) p. 500. Para Fernández, por su parte, es posible definir cada uno de los elementos integrantes de la proporcionalidad de la manera siguiente: "Desde el principio de utilidad (idoneidad), lo que importa es que el medio elegido no sea desde todo punto de vista y a priori absolutamente incapaz o 
Así, según su formulación en el derecho europeo ${ }^{23}$, este principio consiste en un test de cuatro pasos copulativos y escalonados donde se examina la interferencia respecto de derechos fundamentales de una determinada regulación (legislativa o administrativa), que puede resumirse como sigue ${ }^{24}$ : (a) la interferencia con una libertad debe servir a un fin legítimo desde la perspectiva constitucional ${ }^{25}$; (b) idoneidad ${ }^{26}$ : interferencia debe ser apta o adecuada para alcanzar dicho $\mathrm{fin}^{27}$; (c) necesariedad ${ }^{28}$ : la interferencia debe ser la menos restrictiva posible a los derechos fundamentales de entre las alternativas disponibles ${ }^{29}$; y (d) proporcionalidad propiamente tal o stricto sensu $u^{30}$ : la intervención no puede ser excesivamente gravosa. Si las mismas fracasan en el cumplimiento de dichos estándares, entonces la medida puede ser calificada de arbitraria y, por consiguiente, de inconstitucional.

Como hemos explicado, se trata de un test que debe aplicarse de manera escalonada. Por ello, si la medida examinada no cumple con los estándares del primer paso, la inconstitucionalidad del mismo hace innecesario que se examine el cumplimiento del segundo paso y así sucesivamente, de manera que, por ejemplo, si efectuado este análisis de necesariedad, resulta que el Estado podría haber escogido un medio menos lesivo, el medio no habrá satisfecho el examen de necesidad, por no tener el peso suficiente para justificar la restricción del derecho afectado ${ }^{31}$, y por lo tanto, no será necesario examinar su proporcionalidad en sentido estricto ${ }^{32}$. Asimismo, si la medida se considera conforme a la Constitución en el primer paso, entonces nacerá la siguiente exigencia del test, contenida en el segundo paso ${ }^{33}$.

inidóneo ... Desde el punto de vista de la necesidad de la intervención no solo se acepta el fin en un sentido neutro (v.g.: la protección de la flora y la fauna), sino también el concreto grado de efectividad (intensidad, extensión, etc.) con el que el poder público aspira a satisfacerlo... El test de proporcionalidad en sentido estricto, en cambio, introduce el resultado perseguido en su análisis y cuando da positivo -porque el balance sea abiertamente deficitario- impide o bloquea la persecución del fin a través de ese medio (...)”. FERNÁNDEZ (2008) p. 375.

23 Perello (1997) p.70.

24 Sin perjuicio de que este test es coherente con todos los autores y jurisprudencia citada, hacemos presente que, en su explicación, hemos seguido a ENGEL (2001) p. 3.

25 SAONA (2009) p. 4.

26 También denominado “utilidad”, ver Fernández (2008) p. 375, “juicio de adecuación”, ver PERELLO (1997) p.70 y "adecuación técnica”, ver CLÉRICO (2009) p. 39.

27 Perello (1997) p.70.

28 También llamada "examen del medio alternativo" o "requeribilidad". Ver CLÉRICO (2009) p 101. En la tradición norteamericana se vincula al test del medio menos restrictivo o gravoso (least restrictive means), elemento fundamental del strict scrutiny test. Ver SWEET y MATHEWS (2008) y (2010).

29 Para determinar si el medio escogido es el menos gravoso, será menester realizar una comparación entre medios. Esta comparación constituye el núcleo del examen de necesidad. Ver CLÉRICO (2009) p. 101.

30 También denominado "Proporcionalidad en sentido estricto". Este test aborda las cuestiones valóricas que habían sido postergadas en los dos exámenes anteriores. Ver CLÉRICO (2009) pp. 163 y ss.

31 Clérico (2009) p. 102.

${ }^{32}$ Es necesario, en todo caso, prevenir que conforme la Jurisprudencia del Tribunal Constitucional Alemán, existe ciertos casos, en que aun cuando la medida no ha pasado el test de necesidad, se analiza su proporcionalidad en sentido estricto, incluso cuando ello no es imperativo, con el solo fin de incrementar la fuerza de decisión que habla de desproporcionalidad de la medida. Ver CLÉRICO (2009) p. 159.

33 Sin perjuicio de ello, haremos el esfuerzo argumentativo de utilizar todas las partes del test, razón por la cual debe entenderse que la defensa la inconstitucionalidad de un paso diferente al primero está condicionada a la existencia de la debida refutación. 
Al ser el principio de proporcionalidad un instrumento que puede considerarse una herramienta de evaluación costo beneficio - ponderación entre el fin regulatorio y el medio propuesto por el regulador, y como también lo han sostenido Barnes ${ }^{34}$ y Engel ${ }^{35}$-, creemos resulta particularmente idóneo para evaluar la constitucionalidad de las regulaciones económicas.

En efecto, Barnes sostiene que este test ha permitido declarar que una norma que, para prevenir posibles perjuicios al cliente por inadecuado asesoramiento o venta de productos defectuoso, obliga a que todo comerciante adquiera unos conocimientos sumamente genéricos y comunes a cualquier comercio, nada especializados, puede resultar inidónea o inútil para la protección del consumidor; o que la prohibición de ejercer el comercio por el hecho de haber obtenido la formación y experiencia en un determinado país, en el caso concreto, resultó ser una restricción desproporcionada ${ }^{36}$.

\subsection{Hitos En la juRisprudencia del Tribunal CONSTITUCIONAL ESPAÑol (TCE)}

El TCE “importa” el principio de proporcionalidad de la jurisprudencia del Tribunal Constitucional alemán, que es donde se gestó el principio. Como se observará, si bien en un comienzo el desarrollo del principio es bastante parcelado y no es estrictamente un test de cuatro pasos copulativo, hace más de una década que el TCE utiliza este principio de manera completa.

El primer precedente del TCE en materia de proporcionalidad -no constituyéndose en una aplicación pulcra del principio- lo encontramos en la sentencia Rol $N^{\circ} 62$ de 1982. A través de recurso interpuesto ante el TCE, se cuestiona la constitucionalidad de una norma que tipifica como delito la distribución de pornografía. Específicamente se refiere a la distribución de un libro considerado contrario a la moral pública por exceder de la finalidad educativa aducida. Tal libro fue distribuido a librerías para su venta al público, y posteriormente fue exhibido en la Feria del Libro de Madrid de 1979, Sección de Literatura Infantil, siendo sus destinatarios los niños y los padres, y siendo también niños el objeto de algunas fotografías y partes del texto consideradas contrarias a la moral pública. Tales conductas fueron sancionadas, con el comiso de los libros y multas pecuniarias.

En su análisis el TCE parte por citar al Tribunal Europeo de Derechos Humanos caso Handsyde (1976), y señala:

"que la libertad de expresión constituye uno de los fundamentos esenciales de una sociedad democrática que, sin perjuicio de las medidas a que se refiere el art. 10.2 del Convenio de Roma, comprende no solo las informaciones consideradas como inofensivas o indiferentes, o que se acojan favorablemente, sino también aquellas que puedan inquietar al Estado o a una parte de la población. De ahí se deduce

\footnotetext{
34 BARNES (1998).

35 ENGEL (2001).

36 BARNES (1998) p. 18.
} 
-afirma el Tribunal Europeo- que toda formalidad, condición, restricción o sanción impuesta en esta materia debe ser proporcionada al fin legítimo perseguido" 37 .

A continuación el TCE señala que para determinar si las medidas aplicadas eran las necesarias para el fin perseguido, se debe examinar si se ha infringido el principio de proporcionalidad, el cual considera un principio general de derecho ${ }^{38}$. Prosigue señalando que:

"Entendemos que el recto funcionamiento de una sociedad democrática implica que cada institución asuma el cumplimiento de la función que le es propia, lo que nos lleva a la conclusión de que el Tribunal Constitucional ha de circunscribirse a determinar si el principio de proporcionalidad ha quedado infringido, desde la perspectiva del derecho fundamental y del bien jurídico que ha venido a limitar su ejercicio, por ser las medidas adoptadas desproporcionadas para la defensa del bien que da origen a la restricción"39.

Al referirse al caso concretamente, señala que:

"Las observaciones anteriores dan lugar a que no estimemos que la calificación como delito sea desproporcionada si se tiene en cuenta que tal calificación es necesaria en el Derecho español para poder acordar el comiso, según razona el Considerando cuarto de la Sentencia rescindente, medida que estimaron adecuada para la finalidad propuesta tanto la Audiencia Provincial como el Tribunal Supremo, y que este Tribunal no puede calificar de desproporcionada en cuanto se observa fácilmente que la consecución del fin comprende el comiso como medio útil, de entre las penas previstas en el Código Penal. No podemos tampoco estimar como desproporcionada la multa de 20.000 pesetas -que es la cantidad mínima prevista por el art. 431 del Código Penal- ni la pena de arresto mayor en su grado mínimo, máxime cuando el Código Penal contempla la aplicación de la remisión condicional de la condena inferior a un año, dejando en suspenso la ejecución de la pena (art. 92), sin que sobre el cumplimiento efectivo o no de la condena se haya efectuado manifestación alguna. Y por último, tampoco podemos afirmar que resulta desproporcionada la pena de inhabilitación impuesta, en cuanto es la mínima dentro del tipo, su duración temporal aunque amplia no excede del margen de apreciación que corresponde al arbitrio del legislador para la fijación de las penas, y su contenido no excede tampoco de la protección de los bienes jurídicos lesionados dentro de los límites que es necesario reconocer al margen de apreciación que corresponde al arbitrio judicial" ${ }^{40}$.

\footnotetext{
37 Sentencia Tribunal Constitucional español Rol No 62-1982, Fundamento jurídico 5 o.

38 Sentencia Tribunal Constitucional español Rol No 62-1982, Fundamento jurídico 50.

${ }^{39}$ Sentencia Tribunal Constitucional español Rol No 62-1982, Fundamento jurídico 5o.

${ }^{40}$ Sentencia Tribunal Constitucional español Rol No 62-1982, Fundamento jurídico 6º
} 
Un segundo precedente que conviene analizar dentro de la etapa de desarrollo de la proporcionalidad por parte del TCE, lo encontramos la Sentencia Rol Nº 66 de 1985, se interpone ante el TCE un recurso previo de inconstitucionalidad del texto definitivo de la proposición de la Ley Orgánica modificatoria de la Ley Orgánica reguladora del Tribunal Constitucional que suprime el recurso previo de constitucionalidad contra Estatutos de Autonomía y Leyes orgánicas, por considerar, entre otros capítulos de impugnación, que viola el principio de proporcionalidad.

\section{El TCE sostiene que:}

"La desproporción entre el fin perseguido y los medios empleados para conseguirlo solo puede dar lugar a un enjuiciamiento por este Tribunal cuando esa falta de proporción implica un sacrificio excesivo e innecesario de derechos que la Constitución garantiza. Como ello no es así, el argumento no permite sostener, ni la ilicitud del Proyecto, ni, como también el recurrente pretende, su falta de 'adecuación constitucional'41".

Entre mediados de los 80 y durante la década de los 90, el TCE iría sofisticando el uso del principio de proporcionalidad como parámetro de control en diversos ámbitos. Ya entrando en una etapa de mayor desarrollo, podemos citar, a modo de ejemplo, la Sentencia Rol N 186 de 2000, donde el TCE viene a sentar las bases del principio de proporcionalidad en toda su expresión y complejidad, indicando claramente sus subprincipios y aplicándolos al caso concreto. También este nos parece un caso interesante para nuestros propósitos en la medida que se trata de la revisión judicial de una regulación económica en el campo laboral que pondera, por un lado, las facultades de administración empresarial y, por el otro, lesiones potenciales al derecho a la intimidad del trabajador.

En dicha sentencia el TCE parte señalando que:

"ha puesto de relieve la necesidad de que las resoluciones judiciales, en casos como el presente, preserven 'el necesario equilibrio entre las obligaciones dimanantes del contrato para el trabajador y el ámbito -modulado por el contrato, pero en todo caso subsistente- de su libertad constitucional' pues, dada la posición preeminente de los derechos fundamentales en nuestro ordenamiento, esa modulación solo deberá producirse en la medida estrictamente imprescindible para el correcto y ordenado respeto de los derechos fundamentales del trabajador $\mathrm{y}$, muy especialmente, del derecho a la intimidad personal que protege el art. 18.1 CE, teniendo siempre presente el principio de proporcionalidad ${ }^{42}$ ”.

41 Sentencia Tribunal Constitucional español Rol No 66-1985, Fundamento jurídico $1^{\circ}$.

42 Sentencia Tribunal Constitucional español Rol No 186-2000, Fundamento jurídico 6º. 
Señala que la constitucionalidad de cualquier medida restrictiva de derechos fundamentales viene determinada por la estricta observancia del principio de proporcionalidad, así:

"para comprobar si una medida restrictiva de un derecho fundamental supera el juicio de proporcionalidad, es necesario constatar si cumple los tres requisitos o condiciones siguientes: si tal medida es susceptible de conseguir el objetivo propuesto (juicio de idoneidad); si, además, es necesaria, en el sentido de que no exista otra medida más moderada para la consecución de tal propósito con igual eficacia (juicio de necesidad); y, finalmente, si la misma es ponderada o equilibrada, por derivarse de ella más beneficios o ventajas para el interés general que perjuicios sobre otros bienes o valores en conflicto (juicio de proporcionalidad en sentido estricto)... el control que debe realizar este Tribunal de las resoluciones judiciales recurridas en amparo ha de recaer, precisamente en enjuiciar si, como exige la doctrina reiterada de este Tribunal que ha quedado expuesta, el órgano jurisdiccional ha ponderado adecuadamente que la instalación y empleo de medios de captación y grabación de imágenes por la empresa ha respetado en el presente caso el derecho a la intimidad personal del solicitante de amparo, de conformidad con las exigencias del principio de proporcionalidad ${ }^{43}$ ".

Como se observa en este fallo, el análisis que el TCE realiza abarca cada uno de los subprincipios de la proporcionalidad, para luego enfrentarlos al caso de concreto. Ello refleja el estado de madurez al cual ha llegado la aplicación de dicho principio.

\subsection{JurisprudenCia del Tribunal CONSTituCiOnAl CHILENO (TC)}

$\mathrm{Al}$ analizar la jurisprudencia del TC, es posible observar que son variados los fallos en que ha citado el principio de proporcionalidad al momento de justificar tanto la constitucionalidad como la inconstitucionalidad de un precepto legal sometido a su conocimiento, sea a través de la acción de inaplicabilidad o a través de la de inconstitucionalidad.

Sin embargo, la aplicación de este principio, no ha sido homogénea ni es posible extraer una tendencia del Tribunal en esta materia. Si bien son variados (y cada vez más abundantes) los fallos en que el Tribunal menciona el principio como apoyo en sus considerandos, son pocas las sentencias donde es posible encontrar un desarrollo y análisis a cabalidad del principio.

Al revisar las sentencias más relevantes en esta materia, se ha tratado de agruparlas atendiendo al grado y forma en que el TC aplica el principio de proporcionalidad.

En el primer grupo, podemos observar una tendencia de fallos en que se justifica la intervención del derecho en los subprincipios de la proporcionalidad, sin embargo no

43 Sentencia Tribunal Constitucional español Rol No 186-2000, Fundamento jurídico 6o y Sentencia Tribunal Constitucional español Rol No 98-2000, fundamento jurídico $8^{\circ}$. 
los desarrolla ${ }^{44}$. Su raciocinio consiste en señalar que se cumplen los requisitos de la proporcionalidad, por lo que las normas en comento no serían desproporcionadas y, por lo tanto, no serían tampoco inconstitucionales ${ }^{45}$. En palabras del Tribunal:

“...una limitación a un derecho fundamental es justificable, cuando dicho mecanismo es el estrictamente necesario o conveniente para lograr un objetivo constitucionalmente válido, debiendo consecuentemente el legislador elegir aquellas limitaciones que impliquen gravar en menor forma los derechos fundamentales..." 46 .

Dentro de este grupo, encontramos una variante, donde el TC menciona la proporcionalidad, pero la liga a la racionalidad de la distinción, tendencia que se repite, cuando conoce de situaciones ligadas a la igualdad ante la ley ${ }^{47}$ :

“ (...) Además, ha precisado que para poder determinar si se infringe o no la igualdad ante la ley, debe atenderse a la finalidad del legislador para intervenir el derecho fundamental de que se trate, finalidad que debe ser adecuada, necesaria y tolerable para el destinatario de la misma. En otras palabras, la igualdad ante la ley supone analizar si la diferenciación legislativa obedece a fines objetivos y constitucionalmente válidos. De este modo, resulta sustancial efectuar un examen de racionalidad de la distinción; a lo que debe agregarse la sujeción a la proporcionalidad, teniendo en cuenta las situaciones fácticas, la finalidad de la ley y los derechos afectados" 48 .

Una segunda forma en la cual el TC aborda el principio de proporcionalidad, se da cuando utiliza el principio, pero limita su aplicación. Así, establece que la elección del medio más idóneo corresponde determinarlo al legislador, por lo que al rechazar la constitucionalidad de un medio por no ser el más apto, se estaría inmiscuyendo en las facultades propias del poder legislativo ${ }^{49}$.

44 Véase, por ejemplo, Sentencia del Tribunal Constitucional Roles No 1340 (2009) c. 30 y 35; 1204 (2009) c. 13; 541 (2006) c. 15.

45 Podemos señalar, por ejemplo, Sentencia del Tribunal Constitucional Roles No 226 (1995) c. 47; 280 (1998) c. 29; y el más reciente, 519 (2007) c. 9.

46 Sentencia del Tribunal Constitucional Rol No 519 (2007) c. 9.

47 Ver, por ejemplo, Sentencia del Tribunal Constitucional Roles No 1204 (2009) c. 13; 1234 (2009) c. 13.

${ }^{48}$ Sentencia del Tribunal Constitucional Rol No 1234 (2009) c. 13.

${ }^{49} \mathrm{Ha}$ señalado el TC: "Podrá dudarse si el medio empleado es el más adecuado o idóneo. Podrá discutirse si no había otros más aptos para alcanzar igual finalidad, pero no es irracional y se encuentra dentro de los márgenes de estimación propios del legislador suponer que logrará disminuir la frecuencia de ciertos delitos al privar a los responsables de aquellos que no alcanzan a consumarse de un beneficio que asigna para los restantes casos. A esta Magistratura no le corresponde sustituir el juicio propio del legislador ni juzgar la sabiduría o mérito de los instrumentos que emplea, incluso si ellos conllevan diferencias, a condición de que estos instrumentos diferenciadores se presenten como razonablemente idóneos para alcanzar fines constitucionalmente lícitos y se dé la proporcionalidad...”. Sentencia del Tribunal Constitucional Roles No 797 (2008) c. 6; 1295 (2009) c. 37. Dentro de este mismo grupo, encontramos el Rol No 
Siguiendo el análisis es posible encontrar un tercer grupo de fallos, en los cuales el TC enuncia el referido principio y analiza la idoneidad del medio empleado por el legislador ${ }^{50}$.

En esta línea de análisis, en el Rol 755, ha señalado que:

"la imposición de la obligación de defender a determinadas personas de escasos recursos constituye un fin razonable, pero el medio utilizado por el legislador -la gratuidad- puede transformarse en gravoso si se piensa que el abogado deberá dedicarse sin contraprestación pecuniaria alguna a atender asuntos en desmedro de aquellos que ha asumido libremente, lo que puede tornarse en una situación imposible de sostener, y aún de ejecutar satisfactoriamente, más todavía, si se piensa que la obligación se mantendrá hasta el término efectivo del juicio que puede importar un largo período de tramitación. Como se aprecia, para cumplir con el mandato constitucional de dar asistencia legal a quienes no puedan procurársela por sí mismo, el legislador puede emplear el medio -por cierto excepcional y supletorio- de obligar a los abogados a desempeñar esta tarea, pero ello no autoriza la circunstancia de que no se remunere dicha labor profesional. Así, tal carga de gratuidad no aparece como un medio necesario ni se justifica para alcanzar el fin constitucional perseguido..." 51

Siguiendo la búsqueda, se ha detectado todavía una cuarta tendencia, en la cual podríamos decir, que el TC hace un uso parcelado de la proporcionalidad y sus subprincipios. Así, podemos citar la sentencia Rol 1141-2008 que señala que:

“es (...) un medio necesario para dar eficacia a la obligación del propietario colindante, pues resulta un instrumento adecuado para hacer efectiva una conducta que no debe quedar entregada a la libre voluntad del propietario. Si una autoridad administrativa no tuviera la facultad que al Intendente confiere la norma impugnada, quedarían obligados los particulares a accionar judicialmente para exigirla, lo que impondría un alto costo para su disfrute, mismo que probablemente se haría ilusorio (...) En consecuencia, debe concluirse que el precepto legal cuya constitu-

790 (2007), en el cual el TC señala que: "la razonabilidad de la diferencia también exige de la proporcionalidad, pues (...) el legislador no puede tratar de alcanzar objetivos constitucionalmente legítimos de un modo abiertamente desproporcional y, por ende, intolerable para quien experimenta tal diferencia. Al respecto, estos sentenciadores estimarán que la distinción legislativa se encuentra dentro del abanico de tratamientos que pueden considerarse proporcionados, habida cuenta de la situación de hecho en que se encontraban las finanzas públicas del país a esa fecha, la finalidad de la ley que ya ha sido analizada y, particularmente, el hecho de que los bienes y derechos afectados por ella, que se traducen en el reajuste futuro de las pensiones, no pueden, en conformidad al derecho chileno, y según se razonará más adelante, ser considerados como propiedad o derechos adquiridos del pensionado, sino como meras expectativas..." Sentencia del Tribunal Constitucional Rol No 790 (2007) c. 22 y 27.

50 Sentencia del Tribunal Constitucional Roles No 755 (2008) c. 39 y ss.; 1141 (2009) c. 25 y ss.

${ }^{51}$ Sentencia del Tribunal Constitucional Rol No 755 (2007) c. 40 y 41. 
cionalidad ha sido atacada (...) ha empleado un medio necesario, o al menos adecuado, para alcanzar un propósito constitucionalmente legítimo, como es el efectivo disfrute público de bienes que pertenecen a la nación toda ${ }^{52}$ ".

Como hemos sostenido, la necesidad del medio es un test distinto al de idoneidad. Vemos en este considerando que al parecer, al Tribunal le basta con que pase el test de la idoneidad para considerar que la medida es proporcionada y, por lo tanto, constitucional. Al decir esto, quisiéramos entender que lo que hace el TC es aplicar un examen menos exigente de proporcionalidad. Sin embargo, del análisis, no es posible concluir en qué casos aplicaría este test menos exigente.

Para finalizar, es dable señalar que el TC comienza a acercarse a una aplicación completa del principio de proporcionalidad, analizando uno por uno sus subprincipios. Así podemos señalar el Rol 1345-2009, en el cual se pronuncia en un proceso de oficio sobre la inconstitucionalidad de las expresiones contenidas en el inciso primero del artículo 171 del Código Sanitario ${ }^{53}$.

El TC le dedica un desarrollo bastante extenso a la proporcionalidad de la disposición, el cual titula como "Examen de razonabilidad y proporcionalidad de la limitación".

En cuanto a la legitimidad de los fines señala:

"Desde luego, debe tenerse presente que evitar litigación frívola y puramente dilatoria en el cumplimiento de sanciones administrativas es un propósito constitucionalmente lícito. Tal propósito puede servir para dar mayor vigencia a fines que tienen raigambre constitucional..." 54 .

Prosigue estudiando la idoneidad y da tres argumentos para fundamentar que el medio elegido no es idóneo:

“a) Porque en el mecanismo del Código Sanitario, la reclamación judicial no suspende lo resuelto por la autoridad. En efecto, el artículo 172 del Código Sanitario dispone que 'las sentencias que dicte la autoridad sanitaria podrán cumplirse no obstante encontrarse pendiente la reclamación a que se refiere el artículo anterior...'. En consecuencia, no es posible convencer que la consignación previa resulte un modo eficaz de evitar el reclamo injustificado o puramente dilatorio de la multa, pues el reclamante se verá sometido igual a cumplir con la sanción de multa y su litigación -justificada o no- tendrá igualmente por objeto recuperar lo que se ha pagado. La única diferencia es que el pago de la multa, establecido como solve et repete, esto es, como condición de admisibilidad del reclamo judi-

\footnotetext{
52 Sentencia del Tribunal Constitucional Rol No 1141(2009) c. 25 a 27. Ver también Sentencia del Tribunal Constitucional Rol No 1215 (2009) c. 27 y ss.

53 Tal artículo establece que para dar curso a los reclamos judiciales que se interpongan en contra de las sanciones aplicadas por el Servicio Nacional de Salud, se exige previamente que el infractor acompañe el comprobante de haber pagado la multa.

54 Sentencia del Tribunal Constitucional Rol No 1345 (2009) c. 13.
} 
cial, es de pago más seguro que el crédito que emana de una sanción, pero ello en nada ayuda a desincentivar la litigación infundada, pues el mecanismo se aplica por igual a los reclamos fundados y a los infundados. b) Porque el mecanismo en examen en nada impide la litigación frívola. El sancionado con capacidad de pago tendrá la misma tentación de litigación frívola si posteriormente puede recuperar el dinero pagado que si puede evitar el pago. c) En tercer lugar, debe tenerse presente que el derecho sí cuenta con una serie de instrumentos destinados a desincentivar la litigación infundada o puramente dilatoria, y que son idóneos para tales objetivos, pues sí discriminan y desincentivan los libelos que carecen de fundamento plausible. Entre ellos, los exámenes de admisibilidad y la condenación en costas. A diferencia de ellos, la barrera del solve et repete de la especie se aplica con entera independencia de que el juez estime un reclamo bien fundado, que presenta plausibilidad de ser acogido, o si lo estima infundado, temerario o puramente dilatorio. En esas condiciones, no puede sostenerse que el mecanismo sirva a la finalidad que se ha alegado" 55 .

A pesar que la norma en comento no pasa el examen de idoneidad, el TC continúa el análisis de proporcionalidad y revisa la necesariedad. Al respecto, señala que el medio elegido no es el menos gravoso, para los particulares y señala que:

"La legitimidad de los fines obliga a preguntarse si la restricción al acceso a la jurisdicción que se examina resulta exigida, necesaria o siquiera conveniente para la presunción de legalidad de los actos administrativos. Este Tribunal no encuentra el eslabón lógico necesario de la justificación del requisito que impone el inciso primero del artículo 171 del Código Sanitario para el ejercicio de la acción de reclamo, pues la eficacia y el imperio de las resoluciones administrativas dicen relación con su cumplimiento y no con las barreras que se establezcan para reclamar de ellas. El imperio de las resoluciones administrativas podría servir como argumento -más o menos convincente, no es del caso examinarlo ahora- para sustentar que el reclamo judicial no suspenda siempre y de pleno derecho el cumplimiento de la sanción; pero ello es enteramente independiente a establecer una barrera que dificulta severamente la capacidad de reclamar judicialmente lo resuelto por la Administración. Como ya se ha explicado, es perfectamente posible que la barrera de acceso a la justicia desaparezca y luego se establezcan mecanismos destinados a la eficacia directa de lo resuelto por la Administración, mientras ello se discute por la justicia. En la especie, por lo demás, el artículo 172 del Código Sanitario, ya transcrito, autoridad sanitaria no se suspende por el reclamo judicial" 56 .

Para finalizar estudia la proporcionalidad stricto sensu de la norma, lo cual lo lleva a concluir que:

\footnotetext{
55 Sentencia del Tribunal Constitucional Rol No 1345 (2009) c. 13.

56 Sentencia del Tribunal Constitucional Rol No 1345 (2009) c. 14.
} 
"tampoco es posible concluir que la barrera de acceso a la justicia, consistente en la necesidad de consignar la multa, pueda justificarse como un instrumento lícito, idóneo y proporcional para evitar que las multas pierdan eficacia, tanto en su aplicación como en la oportunidad de su pago. Desde luego, y como se ha visto, porque para lograr que la tramitación del reclamo en contra de una sanción no afecte en demasía la eficacia de la multa y la oportunidad en su cumplimiento, el derecho cuenta con una serie de instrumentos relativos a los efectos, suspensivos o no, de la reclamación judicial sobre la ejecución de la sanción. En la especie, el artículo 172 del Código Sanitario establece el más favorable a la Administración y el más severo para el sancionado, como es que lo resuelto por la Administración pueda cumplirse, no obstante la reclamación judicial... ${ }^{57}$

\subsection{Evaluación}

El uso que el TC hace de la proporcionalidad es variado, lo que podría atentar contra el sentido de tener un único test de proporcionalidad. En algunos fallos, como vimos, aplica el test de manera parcelada, señalando que determinar el medio idóneo corresponde al legislador. En otros, analiza el medio, verificando su idoneidad para alcanzar el fin previsto y en la mayoría se basta con mencionar el principio y sus elementos.

La propia experiencia española nos muestra que se trata de una "curva de aprendizaje" larga, esto es, se trata de un desarrollo que requiere de cierta praxis y años de maduración para poder ser aplicado en toda su extensión -un test copulativo y escalonado de cuatro pasos-.

Para algunos, y con razón, el problema de la proporcionalidad como estándar de control regulatorio podría implicar que el Tribunal se transformara en un decisor de política pública, lo cual plantea problemas tanto desde una perspectiva técnica como de legitimidad democrática. En otras palabras, un mal uso de la proporcionalidad conlleva riesgos: el TC no ha sido llamado por la Constitución a transformarse en evaluador de política pública sino a velar por la supremacía constitucional. Así, la ponderación entre medios y fines -sus costos y beneficios en términos de derechos fundamentales- no puede sustituir la ponderación que ha realizado el legislador.

En efecto, y como sostiene Aldunate, este parámetro de control podría llevar al TC a realizar un control de mérito del precepto legal sometido a su conocimiento, control que el TC rechaza ${ }^{58}$, pero que ha utilizado. Aldunate critica dicha incoherencia ${ }^{59}$.

\footnotetext{
57 Sentencia del Tribunal Constitucional Rol No 1345 (2009) c. 15.

${ }^{58}$ En Sentencia del Tribunal Constitucional Rol No 325 (2001) c. 38, sostuvo el Tribunal: "Que, como se advierte, estas alegaciones (...) miran al mérito de la norma, lo que claramente excede la órbita de competencia de este Tribunal. Como reiteradamente se ha declarado en esta sede, dichos juicios de mérito, oportunidad o conveniencia, se encuentran radicados en los órganos de los cuales emana la respectiva regulación. No es en consecuencia procedente que un requerimiento enderezado a este Tribunal se aboque a analizar y decidir más allá de su esfera de atribuciones, que en esta materia importa solo un examen jurídico de constitucionalidad del impugnado decreto, debiendo prescindir de cualquier consideración o raciocinio factual".

${ }^{59}$ Aldunate (2008) pp. 264-267.
} 
Sin embargo, ¿por qué en la aplicación del principio de proporcionalidad el TC puede jugar un rol distinto al que puede jugar un evaluador de política pública (legislador o Dirección de Presupuestos)?

Una posible respuesta podríamos encontrarla en su carácter de actor desinteresado de los resultados del proceso político, lo que le entrega mayores grados de imparcialidad: los jueces tienen naturalmente una posición privilegiada en la preservación de la integridad estructural del proceso democrático -las reglas y condiciones bajo las cuales se busca el poder político y se desarrolla la conversación acerca de los asuntos públicos-, y por ende el tipo de regulación que afecta derechos fundamentales. En otras palabras, los jueces como agentes externos, independientes, ingratos al poder político, deben estar atentos a la capacidad dañina en términos de derechos y libertades individuales del proceso político. Un enfoque como este no es novedoso: su principal impulsor contemporáneo es John Hart Ely ${ }^{60}$.

Por lo demás, en la tradición norteamericana -donde una controversia similar se manifiesta a la hora de evaluar los pros y contras del test del escrutinio estricto (strict scrutiny test) y la ponderación como parámetro de adjudicación (balancing) ${ }^{61}$, en la medida en que la proporcionalidad sea un "procedimiento analítico", esto es, una metodología o un "procedimiento neutral", en sí mismo, no puede generar resultados sustantivos ${ }^{62}$.

Todavía se ve un argumento adicional. Como sostiene Engel, analizando la aplicación del principio de proporcionalidad por parte del TC alemán, se podría encontrar igual o mayor legitimidad en el hecho de que no sea el Tribunal quien comience dicha evaluación y solo reaccione ante el impulso externo de quienes alegan la infracción de la supremacía constitucional o vulneración de derechos constitucionales ${ }^{63}$. Ello, por cierto, no refleja completamente la situación chilena (v.g. existencia del control preventivo obligatorio o controles de oficio), pero muestra luces de reforma del diseño de nuestro sistema de control de constitucionalidad.

Por todo lo anterior es que creemos que el principio de proporcionalidad es particularmente idóneo a la hora de ponderar los costos y beneficios de una regulación que afecta derechos y libertades de naturaleza económica; y, precisamente, por el desarrollo que tiene y puede tener en sede de inaplicabilidad, del análisis de los elementos factuales presentes en un determinado caso, pueden surgir, de manera obvia el juego de costos y beneficios, privados y sociales, que están en juego.

\section{EXPROPIACIÓN REGULATORIA}

La cláusula de expropiación de la Quinta Enmienda de la Constitución de los Estados Unidos ${ }^{64}$, redactada prácticamente dos siglos antes que nuestro estatuto constitucional consolidado en la materia, establece que: “(..) la propiedad privada no será

\footnotetext{
${ }^{60}$ HART Ely (1980).

${ }^{61}$ Ver, por ejemplo, Aleinikoff (1987), Siegel (2006) y Fallon, JR. (2007).

${ }^{62}$ SWEET y MATHEWS (2008) pp. 77-78.

${ }^{63}$ ENGEL (2001) p. 13.

${ }^{64}$ Ratificada el 15 de diciembre de 1791.
} 
expropiada para uso público sin una justa compensación”65 66. Así, en Estados Unidos, es el dominio eminente el que habilita al Estado para adquirir la propiedad de individuos de manera no consensual ${ }^{67}$. Ello requiere de un acto expreso (condemnation) a través del cual el Estado ejerce su poder de dominio eminente, determinando y declarando que cierta propiedad es asignada a un uso público ${ }^{68}$. Adicionalmente, es relevante la sección 1 de la Enmienda XIV ${ }^{69}$.

Con todo, y a pesar de la robustez aparente de estas normas, la cuestión acerca de la expropiación y los límites estatales en la materia no ha resultado ser para nada simple. Los tribunales americanos suelen ser deferentes con los amplios poderes del Estado para regular la propiedad privada cuando la finalidad consiste en la protección del bien común. Sin embargo, como sostienen Miceli y Segerson, algunas regulaciones pueden llegar a ser tan restrictivas que causan una reducción sustancial en el valor de la propiedad privada. Cuando ello ocurre, los tribunales han sostenido en algunas ocasiones que las regulaciones se han transformado en expropiaciones, ordenando, el pago de una indemnización. En este último caso, estamos ante las denominadas expropiaciones regulatorias $^{70}$, debate del que lentamente ha comenzado a tomar nota el ius publicismo chileno en los últimos años ${ }^{71}$.

${ }^{65}$ En la versión original: “(...) nor shall private property be taken for public use without just compensation”. Tomada de GRAFTON (2000) p. 25.

${ }^{66}$ Adicionalmente, en Estados Unidos, casi la totalidad de las constituciones estatales contienen cláusulas de expropiación. MiCELI y SEGERSON (1999) p. 328.

67 Según el Black's LaW Dictionary (2001) p.233, se entiende por dominio eminente: "El poder inherente de una entidad estatal de expropiar propiedad privada, especialmente tierras, y convertirla al uso público, sujeto a una compensación razonable por dicha expropiación.

${ }^{68}$ BLACK'S LAW DiCTIONARY (2001) p. 124.

${ }^{69}$ Ratificada el 9 de julio de 1868, establece que: “(...) Ningún Estado podrá dictar ni dar efecto a cualquier ley que limite los privilegios o inmunidades de los ciudadanos de los Estados Unidos; tampoco podrá Estado alguno privar a cualquier persona de la vida, la libertad o la propiedad sin el debido proceso legal; ni negar a cualquier persona que se encuentre dentro de sus límites jurisdiccionales la misma protección de las leyes". Esta cláusula no tan solo tiene un sentido diferente a aquel de la Quinta Enmienda desde la perspectiva de la protección de la propiedad privada y otros derechos individuales desde la perspectiva de los estados integrantes del Estado Federal, sino que ha pasado a ser fundamental a la hora de entender e interpretar el catálogo de derechos individuales -en especial las diez primeras enmiendas de 1791- establecidos en la Constitución americana (Bill of Rights). Para profundizar en esta cuestión ver, por ejemplo, los magníficos trabajos del profesor de Yale, AKHIL (1998), (2006). Ver también SIEGAN (1980).

70 Miceli y Segerson (1999) p. 336. En el mismo sentido LUeCK y MiCeli (2007) p. 243.

${ }^{71}$ Para Delaveau, la doctrina de la expropiación regulatoria plantea que "mientras en una expropiación tradicional el Estado priva física y formalmente a un propietario de su dominio, en el caso de una expropiación regulatoria se sostiene que el Estado hace efectiva una expropiación de facto a través de una regulación que reduce o elimina sustancial o completamente el valor de la propiedad". DELAVEAU (2006) p. 412. Para Montt, las expropiaciones regulatorias "son el resultado de de una actividad normativa lícita que, de facto, resulta afectar la esencia del derecho de propiedad regulado (...) La limitación al dominio -no indemnizable en principio- es en este caso demasiado severa, ha ido demasiado lejos, produciendo un efecto equivalente al de la expropiación”. MONTT (2005) p. 68. También ver Couso (2002), MARMOlejo (2009). Una mirada crítica interesante la encontramos en ALDUNATE (2006), MoHOR (1989) ya había explorado un concepto similar entre nosotros. También ver, para el debate respecto de la propiedad, las limitaciones al dominio y la procedencia de indemnizaciones, RAJEVIC (1996) y (1998); UGARTE (2001); CORDERO (2006) y (2008). 
El problema central de la expropiación regulatoria dice relación entonces con encontrar la delgada línea que separa aquellas regulaciones no indemnizables derivadas del ejercicio del poder de policía, de aquellas que sí merecen una indemnización (i.e., expropiaciones regulatorias); como asimismo, cuán lejos puede llegar la imposición de cargas públicas a un determinado individuo o grupo de individuos, que deben soportar sacrificios a favor del bien general desproporcionados. Dicha línea no ha sido encontrada por la Corte Suprema americana que ha desarrollado diversos tests para resolver la cuestión.

En este contexto, revisar los hitos más relevantes de la evolución de la jurisprudencia de la Corte Suprema americana en materia de expropiación regulatoria nos parece fundamental, no solo por las lecciones constitucionales de las que podremos tomar nota, sino adicionalmente, la racionalidad económica detrás del debate. Ambas cuestiones, claves a la hora de pensar el fortalecimiento de la revisión judicial de la regulación económica en Chile.

\subsection{JURISPRUDENCIA DE LA CORTE SUPREMA NORTEAMERICANA}

El antecedente jurisprudencial más relevante de la doctrina de la expropiación regulatoria lo encontramos en la sentencia Mugler $v$. Kansas $(1887)^{72}$. Para algunos, esta sentencia se enmarca dentro de una serie de litigios que utilizaron la Cláusula de Expropiación para impugnar acciones estatales ejercidas bajo un amplio poder de policía ${ }^{73}$.

Con todo, sería algunas décadas más tarde en Pennsylvania Coal Co. v. Mahon $(1922)^{74}$, que la doctrina de la expropiación regulatoria empezaría a dar sus primeros pasos.

La Corte Suprema Federal sostuvo en este caso que la ley -que prohibía aquellas formas de extracción de carbón que causara daños a la superficie en áreas edificadas ${ }^{75}$ era una expropiación del dominio de los propietarios del carbón, por lo que procedía una justa compensación, en la medida en que la regulación llegaba "demasiado lejos" en la vulneración de los derechos de las empresas de carbón. Esta sentencia, redactada por el Presidente de la Corte, Oliver Wendell Holmes Jr., no tan solo inauguraba la doctrina de la expropiación regulatoria, sino además, establecía el test de la disminución del valor:

\footnotetext{
72123 U.S. 623 (1887).

73 BEST (2001) p. 3. Los otros casos son Reinman v. Little Rock, 237 U.S. 171 (1915) y Hadacheck v. Sebastian, 239 U.S. 394 (1915).

74260 U.S. 393 (1922).

75 Revisemos los hechos. Las actividades de extracción del carbón subterráneo en la zona de Scranton, Pennsylvania, estaban provocando el hundimiento en la tierra de propiedades y otras estructuras superficiales, algunas veces con consecuencias desastrosas. El 27 de mayo de 1921, el estado de Pennsylvania aprobó la Ley Kohler, que prohibió aquellas formas de extracción de carbón que causara daños a la superficie en áreas edificadas. En la práctica impedía la minería del carbón en áreas urbanas. El problema de constitucionalidad que se planteaba con esta ley estaba dado por la circunstancia de que la mayoría de los propietarios de los terrenos superficiales, habían comprado sus tierras bajo una cláusula que establecía que las compañías de carbón se reservaban el derecho a extraer el recurso bajo dichos terrenos y no eran responsables por los daños que causaran en la superficie. La compañía minera ganó en primera instancia, pero perdió cuando el caso fue revisado por la Corte Suprema de Pennsylvania. Si bien esta última reconoció que la compañía minera tenía un contrato y derechos de propiedad, señaló que tales derechos carecían de valor frente al poder de policía. Los hechos del caso tomados de FISCHEL (1995) pp. 13-15.
} 
"Difícilmente el Estado podría funcionar si debiese pagar toda disminución de valor de una propiedad, vinculado a cada cambio legal. Como ha sido reconocido largamente, algunos activos (values) son disfrutados bajo una limitación implícita y deben ceder al poder de policía. Pero obviamente la limitación implícita debe tener límites, o las cláusulas de contratos y debido proceso se habrán esfumado. Un factor para considerar a la hora de determinar dichos límites consiste en la extensión de la disminución. Cuando alcanza cierta magnitud, en casi todos los casos, por no decir todos, debe ejercerse el dominio eminente y compensarse para mantener la validez de dicha ley. La cuestión depende de los hechos particulares. El mayor peso será dado al juicio de la legislatura, pero siempre estará abierto a las partes interesadas el poder sostener que la legislatura ha ido más allá de su poder constitucional"76.

Así, en opinión de la Corte, el supuesto subyacente consistía en evitar que el poder de policía sustituyera la cláusula constitucional de dominio eminente/expropiación, como asimismo infringiera las normas constitucionales referidas al respeto del derecho de contratos (artículo I, sección 10) y el debido proceso (Enmienda XIV). Si se pasaran a llevar estas limitaciones, la revisión judicial sobre el poder de policía estatal tendría un sentido meramente teórico. Para ello, sin embargo, la disminución de valor del activo afectado por la nueva regulación debía ser considerable para ganar la atención de la Corte ${ }^{77}$.

Bajo este supuesto, el juez Holmes sostuvo -en la frase más recordada del fallo-: "La regla general al menos es que, mientras la propiedad puede ser regulada hasta cierto punto, si la regulación llega demasiado lejos, será reconocida como una expropiación"78.

Con todo, tanto la frase "llega demasiado lejos" como la de "disminución de valor” no entregan parámetros claros. En efecto, Holmes no entregó definiciones precisas o un estándar general de control de las regulaciones que se transformaban en expropiatorias, ello quedaría para una determinación caso a caso ${ }^{79}$. Su objetivo principal, sin embargo, consistió en mostrar que algún límite tenía el poder de policía ${ }^{80}$.

La racionalidad económica de Holmes también estaba implícita en su reconocimiento de que "la tendencia natural de la naturaleza humana" 81 hacía que una regla de no compensación llevaría a una sobrerregulación hasta el punto en que "la propiedad privada desaparecería"82. Para Miceli y Segerson, ello refleja el reconocimiento de Holmes de la necesidad de balancear entre los costos de compensación (conteniendo al Estado) y sus beneficios (protección de la propiedad privada y limitar los excesos estatales) ${ }^{83}$.

\footnotetext{
76260 U.S. 393, 413 (1922).

77 FISCHEL (1995) pp. 16-17.

78260 U.S. 393, 415 (1922).

79 Miceli y SEgERSON (1999) p. 343.

${ }^{80}$ FisCHEL (1995) p. 20-21.

81260 U.S. 393, 413 (1922).

82260 U.S. 393, 413 (1922).

83 Miceli y Segerson (1999) p. 343.
} 
Pero este balance costo-beneficio tiene una dimensión más profunda, como queda de manifiesto a continuación en la opinión de Holmes:

"En general no es común que las desgracias del hombre o sus necesidades vayan a justificar que transfiera estos daños a los hombros de su vecino (...) Estamos en peligro si nos olvidamos que el fuerte deseo público de mejorar la condición pública no resulta suficiente para garantizar la obtención de este deseo, mediante un atajo distinto a la vía constitucional de pagar por ese cambio. Como hemos sostenido, esta es una cuestión de grado -y por tanto no puede quedar propensa a proposiciones generales- (...) Pero la cuestión de fondo es sobre quien deben recaer las pérdidas de los cambios deseados. En tanto particulares o comunidades han aceptado tomar el riesgo de adquirir solamente derechos de superficie, no podemos ver que el hecho de que dicho riesgo se ha transformado en un peligro justifique la entrega de mayores derechos que los que compraron" 84 .

Ello implica considerar que para el Estado no basta pasar el estándar de racionalidad o un análisis costo-beneficio por detallado que sea este último, para evitar tener que compensar. Así, la obligación de compensación "no mana del escepticismo judicial acerca de la racionalidad de una ley, sino del sentido de que es injusto redistribuir derechos de propiedad mucho tiempo después de su establecimiento inicial" 85 .

Por su parte, en su voto de disidencia, el juez Brandeis sostuvo que si el uso de un predio es en sí mismo nocivo, peligroso o causa un daño público, el legislador es libre de regular su uso sin compensación alguna, aun cuando el poder de policía pueda causar pérdidas en el propietario. Este argumento es conocido como el test de excepción de daño (nuisance exception), que sería desarrollado en Lucas (1992). Asimismo defendió, siguiendo Mugler v. Kansas (1887), la aplicación de la doctrina del uso nocivo y la amplitud del poder de policía ${ }^{86}$.

84260 U.S. 393, 415 (1922).

85 FISCHEL (1995) p. 22.

86 En efecto, Brandeis sostuvo que: "Una restricción impuesta para proteger la salud, la seguridad o la moral pública de amenazas peligrosas, no es una expropiación. La restricción en cuestión en este caso es solo la prohibición de un uso nocivo. El Estado no se apropia ni hace ningún uso de ella (...) Se ha dicho que un hecho a considerar al determinar si el poder de policía ha excedido sus límites está en la medida en que resulte una disminución de valor, y que en este caso la restricción destruya derechos de propiedad existentes y contratos. Pero el valor es relativo. Si vamos a considerar el valor del carbón mantenido en el lugar por la restricción, deberíamos compararlo con el valor de todas las otras partes de la propiedad. La ley estaba claramente dirigida a un propósito público, y parece asimismo evidente que el solo aviso de la intención de extraer el mineral no asegura la seguridad pública (...) Se ha dicho que la ley no se puede sustanciar como un ejercicio del poder de policía donde el derecho a extraer el carbón en cuestión ha sido reservado (...) La conclusión parece descansar sobre la hipótesis que en orden de justificar tal ejercicio del poder de policía, debe haber 'un equilibrio en las ventajas recíprocas' tanto respecto del dueño de la propiedad restringida como del resto de la comunidad, y que tal reciprocidad en este caso estaba ausente (...) La reciprocidad de ventaja es una consideración importante, e incluso podría ser esencial, donde el poder del Estado es ejercido para el fin de conceder beneficios sobre la propiedad de un vecindario, como en los proyectos de drenaje, o sobre predios colindantes, como en la provisión de una pared medianera. 
Por más de cinco décadas, la jurisprudencia sobre expropiación regulatoria no fue revisada ni mayormente sofisticada por la Corte Suprema ${ }^{87}$. Sería a finales de los 70, en Pennsylvania Central Transportation Co. v. City of New York $(1978)^{88}$, en que el juez Brennan, escribiendo por la Corte, propondría un nuevo test compuesto de tres componentes o criterios para determinar cuando una regulación ha ido muy lejos al punto de convertirse en una expropiación -el primero vinculado a la "doctrina del uso nocivo" de Mugler (1887), los otros dos al "test de disminución del valor" de Penn Coal (1922)-; test que revolucionaría esta área ${ }^{89}$. En efecto, dicho magistrado, sostuvo que una regulación puede frustar de tal manera las expectativas económicas razonables de la inversión (investment-backed expectations) que puede equivaler a una expropiación, analizados los hechos del caso ${ }^{90}$.

En efecto, el juez Brennan sostuvo -en lo que ha pasado a ser el núcleo del falloque:

"Al involucrarse en el análisis ad hoc, factual, la decisión de la Corte ha identificado diversos factores que tienen una significancia particular. El impacto económico de la regulación en el reclamante y, particularmente, la extensión en que la regulación ha interferido con diversas expectativas de retorno de inversión son, por supuesto, consideraciones relevantes" ${ }^{\prime 1}$.

Profundizando, podemos señalar que, respecto del primer componente del test, el juez Brennan sostuvo por la Corte que:

Pero cuando el poder de policía es ejercido, no para conceder beneficios a favor de propietarios sino para proteger a la sociedad de algún detrimento o peligro, no hay en mi opinión, en ese caso, lugar para considerar ventajas recíprocas. Ahí no hay ventaja recíproca para el propietario restringido de usar ya sea sus estanques de petróleo, botillería, salón de billar, etc.; a menos que sea la ventaja de vivir y hacer negocios en una comunidad civilizada. Esa ventaja recíproca es dada por la ley a los operadores de carbón”. 260 U.S. 393, 417-19 (1922).

87 BEST (2001) p. 4. Casos intermedios relevantes entre Penn Coal (1922) y Penn Central (1978) son: Nectow v. Cambridge, (1926); Miller v. Schoene (1928); United States v. Causby (1946); Armstrong v. United States (1960); Goldblatt v. Hempsted (1962); Griggs v. County of Allegheny (1962); United States v. Fuller (1973).

88438 U.S. 104 (1978).

${ }^{89}$ MiCeli y Segerson (1999) p. 345.

${ }^{90}$ La Comisión de Preservación de Hitos de la ciudad de Nueva York, designó a la compañía llamada Grand Central Terminal precisamente "hito de la ciudad", quedando en consecuencia sujeta a no ser destruida o modificada exteriormente sin una revisión previa de la comisión. En 1968, Penn Central Transportation Company, presionada financieramente y en un intento por conseguir dinero, vendió el derecho a levantar un rascacielos voladizo sobre el terminal. La Comisión dictaminó que el propósito de Penn Central no cumplía con la regulación, y canceló la venta. Luego de esto Penn Central demandó a la ciudad por la supuesta expropiación realizada por parte de la Comisión sin la debida compensación. Es de presumirse que Penn Central tenía en mente la posibilidad de que la ciudad quisiera comprar los derechos de construcción en propiedades designadas como tesoros históricos. Primero se asumió que alguna compensación debía ser exigida por la preservación del patrimonio histórico. Segundo, se elaboró y defendió un sistema de derechos de desarrollo transferibles como una adecuada compensación. Penn Central perdió en la apelación, donde la corte falló a favor de la ciudad. Los hechos del caso tomados de FISCHEL (1995) pp. 49-50.

91438 U.S. 104, 125 (1978). 
"Los apelantes primero observaron que el espacio aéreo sobre el Terminal constituye un interés valuable sobre la propiedad. Afirmaron que la "Ley de Sitios de Interés" los privó de cualquier uso remunerado de su derecho aéreo sobre el Terminal y que, con independencia del valor del resto de la propiedad, la ciudad se apropió de sus derechos a este espacio aéreo suprayacente, lo que les daba derecho a una indemnización justa determinada por el justo valor de mercado de ese derecho aéreo (...) Nuestra jurisprudencia no divide una propiedad en segmentos discretos e intenta determinar si los derechos en un segmento particular han sido completamente abrogados. Al decidir si una acción particular del gobierno ha producido una expropiación, esta Corte más bien se centra en el carácter de la acción y en la naturaleza y extensión de la interferencia en los derechos sobre la propiedad como un todo" 92 .

Respecto del segundo y tercer componente, vinculado a las expectativas económicas razonables de la inversión, pero en particular con la extensión de la disminución del valor fruto de la acción estatal, sostuvo:

"El efecto de la Ley de Sitios de Interés es simplemente prohibir a los apelantes o a cualquier otra persona, ocupar porciones del espacio aéreo sobre el Terminal, mientras que les permite usar el resto de la propiedad en una forma lucrativa (...) La ley de Nueva York no interfiere de ningún modo con el uso presente del Terminal. Su designación como "sitio de interés" contempla el que los apelantes puedan seguir usando la propiedad precisamente como ha sido usada durante los 65 años anteriores; como un terminal de trenes que mantiene espacio de oficinas y concesiones. Así la ley no interfiere con lo que debe ser considerado como las expectativas principales de Penn Central sobre el uso de la propiedad, o su aptitud, para obtener un "retorno razonable" de su inversión"93.

Por su parte, la disidencia del juez Renquhist, al cual se sumaron el Presidente de la Corte juez Burger y el juez Stevens, analizó -al igual como lo hiciera Holmes en Penn Coal (1922) - la cuestión acerca de quién debería soportar la carga de la regulación, como asimismo el carácter de la invasión regulatoria ${ }^{94}$.

92438 U.S. 104,125 (1978).

93438 U.S. 104, 127 (1978).

94 Sostuvo el voto de minoría: "La cuestión en este caso es si el costo asociado a la decisión adoptada por la ciudad de Nueva York, para preservar un limitado número de 'hitos' dentro de sus límites, debe ser de cargo de todos los contribuyentes o si puede ser impuesto enteramente en el dueño de la propiedad. Mientras que los propietarios vecinos son libres de usar su tierra y sus 'derechos aéreos' de cualquier forma consistente con los límites generales de la ciudad, Penn Central, sin el permiso de los apelados, debe mantener para siempre su propiedad en el estado actual. De esta manera la propiedad ha sido sometida a una servidumbre que no ha sido libremente contraída ni impuesta a los vecinos o a similares propiedades (...) Una pérdida multimillonaria ha sido impuesta en los apelantes, es única y no se anula por ningún beneficio por la conservación de los otros 400 edificios en la ciudad de Nueva York. Los apelados han impuesto un costo sustancial en menos de 1/10 del uno por ciento de los edificios en Nueva York para el 
Tras Penn Central el fallo más relevante en la jurisprudencia de la expropiación regulatoria sería Lucas $(1992)^{95}$, sin embargo, encontramos diversos fallos que merecen ser considerados en la evolución y sofisticación hacia Lucas: Agins v. City of Tiburon $(1980)^{96}$; Loretto v. Teleprompter Manhattan (1987)97; Nollan v. California Coastal Commission (1987) ${ }^{98}$; y, Keystone Bituminuos Coal Association v. DeBenedictis (1987)99. Otros fallos relevantes en este "set" intermedio de casos previos son Hodel v. Irving ${ }^{100}$ y First English Evangelical Church v. County of Los Angeles ${ }^{101}$.

Así, llegamos a Lucas v. South Carolina Coastal Council (1992)102, un caso interesante de regulación urbana, como lo demuestran los hechos del mismo ${ }^{103}$. El juez Scalia,

beneficio general de su población. Exactamente es para este tipo de imposición de los costos generales sobre unos pocos que está dirigida la protección de la 'cláusula de expropiación' (takings clause) (...) Es precisamente este tipo de discriminación la que prohíbe la Quinta Enmienda. (...) Un apoderamiento no se transforma en un ejercicio del poder de policía no compensable simplemente porque el gobierno permite al propietario algún uso razonable de su propiedad. Es el carácter de la invasión, no la magnitud del daño resultante de ella, siempre que el daño sea considerable, lo que determina si el asunto constituye una expropiación”. 438 U.S. 104, 147-149 (1978).

95505 U.S. 1003 (1992).

96447 U.S. 255 (1980). En este fallo se introdujo el test de "dos frentes", el cual consiste en que la regulación de uso del suelo no causa una expropiación si es que (a) adelanta sustancialmente un interés legítimo del Estado; y (b) no priva al dueño de un uso económicamente viable de su propiedad. DRAEGER (2001) p. 374.

97458 U.S. 419 (1982). En esta sentencia, distinguiéndose los diversos tipos de invasiones a la propiedad en que podría caer la acción estatal, se reconoció, por primera vez, la ocurrencia de una expropiación per se cuando el carácter de la acción estatal es una permanente ocupación física de la propiedad, incluso si la interferencia es mínima. DRAEGER (2001) p. 376. Sostuvo el juez Marshall: "El precedente confirma una distinción entre una ocupación física permanente, una invasión física breve en su ocupación, y una regulación que solo restringe el uso de la propiedad”. 458 U.S. 419, 435 (1982).

98483 U.S. 825 (1987). Esta sentencia, redactada por el juez Scalia, intenta demostrar que existen ciertos esquemas regulatorios tan cercanos en espíritu al dominio eminente, que deben ser tratados como expropiaciones. FISCHEL (1995) pp. 57-59. Nollan destaca por haber extendido el concepto de expropiación per se de Loretto y desarrollado el primer componente de "adelanto sustancial" del test de "dos frentes" de Agins, componente que será invalidado varias décadas más tarde en Lingle v. Chevron USA (2005). BEST (2001) p. 5.

99480 U.S. 470 (1987). En Keystone, la Corte aplicó el test desarrollado en Penn Central concluyendo que la prohibición a una mina de carbón que busca proteger el hundimiento de la superficie no constituía una expropiación. La Corte enfatizó que el análisis de una expropiación regulatoria considera la "propiedad como un todo" y no solo la porción de la propiedad que sufre la prohibición de uso. También en esta sentencia se elaboró el concepto de que el Estado está protegido de la impugnación por expropiación cuando ha actuado para prohibir el uso "perjudicial contra la comunidad" evitando "actividades equivalentes a dañosas" (nuisance-like activity). BEST (2001) p. 6.

100481 U.S. 704 (1987); confirmado en Babbitt v. Youpee (1997).

101482 U.S. 304 (1987). Este último interesante al desarrollar el concepto de "expropiación temporal".

102505 U.S. 1003 (1992).

103 Revisemos los hechos. Como muchos otros estados, Carolina del Sur adoptó en los 70 regulaciones para controlar el desarrollo del borde costero, en parte porque la playa era objeto de erosión y daños por parte de tormentas. Carolina del Sur endureció su regulación en 1988, a través de la Beachfront Managment Act, para prevenir cualquier desarrollo en una "zona muerta". David Lucas compró en 1986 por \$975,000 dos de los últimos lotes sin construir en un complejo cerrado llamado "Wild Dunes" en la Isla de las Palmas, los cuales estaban situados en la zona muerta. Sin embargo, ya habían sido construidas varias casas en la zona muerta a ambos costados de los lotes de Lucas. Las casas de playa existentes no fueron afectadas por la legislación, salvo en cuanto a que no les estaría permitido reconstruir si fueran destruidas por un huracán. Lucas no tuvo que 
escribiendo por la Corte, sostuvo que "cuando el dueño de la propiedad ha sido llamado a sacrificar todo uso económicamente beneficioso en nombre del bien común, esto es, dejando su propiedad económicamente inútil, ha sufrido una expropiación”104. Para Miceli y Segerson, la Corte sostuvo básicamente que la regulación había cruzado claramente el umbral establecido por el test de "disminución del valor" y que, por tanto, se estaba ante una expropiación. Sin embargo, la Corte no ofreció una guía clara para identificar la ubicación exacta de dicho umbral ${ }^{105}$.

Para Draeger, cuando la Corte comenzaba tradicionalmente su balance bajo los factores de Penn Central, la unidad de propiedad a ser escrutada era la totalidad de ella. Sin embargo, el caso Lucas cambió esta regla de la totalidad. El juez Scalia señaló que era poco claro cómo debía considerarse lo anterior, en atención a si en una situación en que el propietario perdiera una larga porción de su propiedad se entendería como que se le ha privado de todo uso económicamente beneficioso de la porción gravada, o si debía tomarse como que ha sufrido una simple disminución en el valor de la propiedad como un todo. Pero a pesar de ello se abstuvo de dar una definición nueva relativa a la porción de tierra que debía considerarse como relevante por lo que aparentemente no se apartó del uso de la regla de la totalidad ${ }^{106}$.

Otro aspecto destacado de Lucas es que reconoció la regla de "excepción de daño" (nuisance exception) que sostiene que no procede una compensación en caso de regulaciones que impidan actividades que serían clasificadas como actividades molestas (nuisances) bajo el derecho común estadual ${ }^{107}$.

Por otra parte, también son interesantes las disidencias respecto de la adopción de esta regla. El juez Stevens, por ejemplo, criticó la regla de la privación de todo uso económicamente beneficioso por ser totalmente arbitraria, ilustrando que "un propietario cuya propiedad disminuye de valor en un $95 \%$ no recobra nada, mientras que el que sufre una completa pérdida de valor recobra el valor total de la propiedad"108. En un sentido similar, el juez Blackmun afirmó que el reclamante aún puede gozar de otros atributos de la propiedad, como el derecho a excluir a otros, uno de los más importantes en la esfera de los derechos con que comúnmente se caracteriza la propiedad ${ }^{109}$.

esperar por el huracán. El valor de su propiedad fue eliminado por las regulaciones de 1988, mientras que sus numerosos vecinos soportaban poco o nada el gravamen. Lucas, reconociendo el derecho del estado para establecer dicha regulación, sostuvo, sin embargo, que reducía en tal magnitud el valor de su propiedad que se transformaba en una expropiación que debía ser compensada. Un tribunal de primera instancia acogió en agosto de 1989 el argumento de Lucas. Sin embargo, la Corte Suprema de Carolina del Sur falló a favor del estado, basado en el poder regulatorio amplio que ostentaban los gobiernos estatales y locales en la materia. La Corte Suprema Federal, desechó esta argumentación. Los hechos del caso tomados de FISCHEL (1995) pp. 59-60; MiCELI y SEGERSON (1999) pp. 343-44).

104505 U.S. 1003,1010 (1992).

105 MiCeli y SEgERSON (1999) p. 344.

106 DRAEGER (2001) p. 378.

107 LUECK y MiCELI (2007) p. 243.

108505 U.S. 1003, 1064 (1992)

109505 U.S. 1003, 1036-1061 (1992) 
Con posterioridad a Lucas, y hasta nuestros días, han sido diversos los fallos en que la Corte ha ido puliendo los diversos estándares que ha ido desarrollando desde el mítico Penn Coal (1922), por ejemplo, Palazollo v. Rhode Island (2001) ${ }^{110}$, Tahoe-Sierra Preservation Council v. Tahoe Regional Planning Agency (2002) ${ }^{111}$, Brown v. Legal Foundation of Washington (2003) ${ }^{112}$ o Lingle v. Chevron U.S.A. INC. (2005) ${ }^{113}$.

Este último caso es interesante porque le quitó toda validez al test de "dos frentes" establecido en Agins (1980). En Lingle, la jueza O'Connor escribiendo por una Corte unánime, dejó en claro que no existe nada semejante a un test de "adelanto sustancial”, ello en directa relación a la jurisprudencia de algunos tribunales inferiores que le había dado autonomía a este test respecto de los tests desarrollados en Penn Central, Loreto y Lucas.

En este caso los tribunales inferiores habían invalidado una ley de control de rentas de Hawaii como una expropiación regulatoria no tolerada por la Constitución sobre la base que no "adelantaba sustancialmente" el interés estatal esgrimido en controlar los precios de las gasolinas. Sostuvo la Corte que:

"Aunque algunos de nuestros precedentes sobre expropiaciones han invocado la fórmula de 'adelanto sustancial' establecido en Agins, esta es la primera oportunidad para considerar su validez como un test expropiatorio autónomo (freestanding). Hemos concluido que esta fórmula no tiene cabida en nuestra jurisprudencia de expropiación. En claro contraste (con los tests de expropiación regulatoria de Loretto, Lucas y Penn Central) el "adelanto sustancial" no nos dice nada acerca de la magnitud o el carácter del gravamen que una regulación particular impone sobre el derecho de propiedad privada. Tampoco provee información acerca de cómo un gravamen regulatorio es distribuido entre los propietarios. En consecuencia, este test no ayuda a identificar aquellas regulaciones cuyos efectos son funcionalmente comparables a la apropiación o invasión de la propiedad privada por parte del estado; no se encuentra relacionada en nada con el texto de la Cláusula de Expropiación ni con la justificación básica para permitir que las acciones regulatorias sean impugnadas bajo este Cláusula" ${ }^{114}$.

Más interesante aún es el tratamiento que da a una serie de complejidades que enfrenta la revisión judicial en esta área desde la perspectiva regulatoria, incluida la competencia institucional de la Corte y los jueces para zanjar las controversias presentadas:

“El test de 'adelanto sustancial' también presenta serias dificultades prácticas. Puede ser leído como demandando una revisión más estricta entre fines y medios de virtualmente cualquier regulación de la propiedad privada. Si fuese interpretado de esa manera, requeriría que las cortes examinaran la eficacia de una vasta

\footnotetext{
110533 U.S. 606 (2001).

111535 U.S. 302 (2002).

112538 U.S. $216(2003)$

113544 U.S. 528 (2005).

$114 \mathrm{http}: / /$ caselaw.lp.findlaw.com/scripts/getcase.pl?navby=CASE\&court=US\&vol=544\&page=528
} 
extensión de regulaciones federales y estaduales -tarea para la cual las cortes no están bien equipadas-. Más aún, empoderaría -y posiblemente requeriría- que las cortes sustituyeran con sus juicios predictivos aquel de las legislaturas electas y las agencias expertas" 115 .

De hecho, para resolver la presentación de expropiación de Chevron, la Corte de Distrito tuvo que elegir entre las opiniones de dos economistas acerca de si la ley de control de rentas de Hawaii ayudaría a prevenir la concentración y precios sobrecompetitivos en el mercado estatal de la gasolina. Encontrando a un experto 'más persuasivo' que el otro, la corte (de distrito) concluyó que la estrategia regulatoria elegida por la legislatura de Hawaii no cumpliría con dichos objetivos:

"Encontramos estos procedimientos sorprendentes, por decir lo menos, dado que por largo tiempo hemos evitado un nivel de escrutinio tan alto a la hora de analizar impugnaciones basadas en el debido proceso sustantivo a regulaciones estatales. Las razones para ser deferentes con el juicio de la legislatura acerca de la conveniencia y el nivel de efectividad de las acciones regulatorias son hoy en día bien conocidas, y creemos que tienen plena aplicación aquí"116.

\subsection{JURISPRUDENCIA DEL TC}

Si bien el debate respecto de la determinación de la frontera entre limitación y privación del dominio no es nuevo para el $\mathrm{TC}^{117}$, como tampoco para la Corte Supre$\mathrm{ma}^{118}$, y es posible vincular algunas sentencias al debate de la expropiación regulatoria - como lo ha hecho alguna destacada doctrina ${ }^{119}$ - creemos que el precedente más relevante en la aplicación de una doctrina o test de expropiación regulatoria desde la perspectiva del TC -y que por tanto se diferencia de otros enfoques jurisprudenciales para enfrentar el debate en torno a la frontera limitación-privación de dominio o sus atributos esenciales-, son las sentencias denominadas doctrinariamente "Peajes de transmisión eléctrica”, STC Rol No 505-2006 y 506-2006, ambas de 6 de marzo de 2007 e idénticas en lo sustancial.

Lo anterior nos parece problemático en circunstancias que creemos este test tiene un gran potencial para transformarse en un parámetro de control sofisticado a la hora de

\footnotetext{
$115 \mathrm{http}: / /$ caselaw.lp.findlaw.com/scripts/getcase.pl? navby=CASE\&court=US\&vol=544\&page=528

116 http://caselaw.lp.findlaw.com/scripts/getcase.pl? navby=CASE\&court=US\&vol=544\&page=528

117 Ver, por ejemplo, las Sentencias del Tribunal Constitucional Roles No 245-246 (1996), "Playas I"; 253

(1997) "Cesiones gratuitas de terrenos"; 334 (2001), "Rentas Vitalicias"; 1141 (2009) "Playas II"; y 1215

(2009) "Playas III". "Playas II", es quizás el heredero más cercano de "Peajes de transmisión eléctrica”. En efecto, el considerando $18^{\circ}$ se remite a los considerandos $20^{\circ}$ y $21^{\circ}$ de los fallos Roles No 505 (2007); 506 (2007).

118 Ver, por ejemplo, "Comunidad Galletué con Fisco" (1984) e "Inmobiliaria Maullín Limitada con Fisco" (2004).

119 Ver, por ejemplo, Aldunate (2006); Fermandois (2006); Romero (2008); y BoetTiger (2009). La mayoría de estos autores ve en los trabajos de RAJEVIC (1996) y UGARTE (2001), un diagnóstico certero de las disyuntivas en la materia.
} 
evaluar la constitucionalidad de ciertas regulaciones que por su magnitud, extensión afectan derechos fundamentales, en particular el derecho de propiedad y la igualdad ante las cargas públicas.

En el caso de STC Rol No 505-2006, se trata de un recurso de inaplicabilidad ante el Tribunal Constitucional (en el contexto de un recurso de casación en la forma relativo al fallo arbitral), para que este declare la inaplicabilidad por inconstitucionalidad del art. $3^{\circ}$ transitorio de de la Ley No 19.940, que hacía aplicable la nueva regulación de la transmisión eléctrica a la relación contractual que existía entre empresas de generación eléctrica y HQI Transelec Chile, la compañía de transmisión eléctrica. La compañía de generación eléctrica aludida reclamó que la nueva regulación de la transmisión eléctrica, al pretender imponer por sobre una relación regida por un contrato anterior válidamente celebrado y con vigencia hasta el año 2028, vulneraba el derecho de propiedad sobre un bien incorporal, esto es, el derecho adquirido en virtud de un contrato a usar, por un determinado precio o peaje, las instalaciones de transmisión eléctrica de la empresa de transmisión ${ }^{120}$.

Destaca, en primer lugar, el que si bien el Tribunal es contundente en sostener que el numeral $24 \mathrm{del}$ art. $19^{\circ}$ de la Constitución establece "un mismo y único estatuto de protección para ambas especies de propiedad"121, señala asimismo que "los derechos de propiedad sobre cosas incorporales que nacen de contratos entre privados no están inmunes a ser limitados o regulados, en conformidad a la Constitución"122, no obstante que "el origen contractual de un derecho de propiedad hará más improbable justificar el interés social que legitima alterarlo, pero tal origen no es, por sí mismo, un impedimento de regulación" 123 .

Buscando determinar en seguida si las limitaciones y regulaciones establecidas en la norma examinada constituyen una limitación y regulación, para la requerida, o una expropiación, para la requirente, sostiene, como punto de partida que podríamos denominar metodológico, que dicha distinción debe ser escrutada a la luz de lo dispuesto en el artículo 19 No 24 y no situarla, "como ha hecho alguna doctrina, en torno a parámetros que la Constitución chilena no consagra expresamente, como es de la llamada intangibilidad de los contratos; a cuestiones que solo tienen consagración legal en materia civil" ${ }^{24}$.

Entrando derechamente a elaborar parámetros para abordar la distinción, sostiene en el considerando $22^{\circ}$, en primer lugar, que esta ha sido una de las que mayor debate ha suscitado en la doctrina y respecto de la cual han debido pronunciarse las jurisdicciones constitucionales más influyentes del mundo; en segundo lugar, que es posible distinguirlas conceptualmente ${ }^{125}$; y finalmente, en lo que más interesa, que:

\footnotetext{
120 Romero (2008) p. 22.

121 Sentencia del Tribunal Constitucional Rol No 505 (2007) c. 17.

122 Sentencia del Tribunal Constitucional Rol No 505 (2007) c. 18.

123 Sentencia del Tribunal Constitucional Rol No 505 (2007) c. 19.

124 Sentencia del Tribunal Constitucional Rol No 505 (2007) c. 20.

125 Sostuvo el Tribunal en el mencionado considerando que: "En general puede decirse que conceptualmente ambas figuras pueden distinguirse, pues un acto de privación tendrá por objeto despojar, quitar, sustraer una determinada propiedad de su titular, mientras el acto regulatorio tendrá por función determi-
} 
“(...) si el acto de regulación o de limitación afecta en una magnitud significativa las facultades o atributos esenciales del propietario, este podrá argumentar que se le ha privado del dominio, pues ya no puede hacer las cosas esenciales que este conllevaba. Se trata de lo que el derecho comparado ha denominado desde hace casi un siglo "regulaciones expropiatorias". Nuestra Carta Fundamental contiene una distinción muy útil para acometer esta tarea, pues trata como equivalentes la privación de la propiedad con la de cualquiera de sus atributos o facultades esenciales""126.

Concluye el Tribunal este trascendental considerando sosteniendo que respecto de la equivalencia realizada por la Constitución, existe un precedente en donde se estimó que ciertas regulaciones resultan inconstitucionales por privar a los propietarios de atributos esenciales de su dominio ${ }^{127}$.

Así, para el TC, la magnitud de la regulación no resulta entonces indiferente:

"Por una parte porque toda regulación o limitación priva al propietario de algo. A partir de la regulación, alguna autonomía, privilegio, ventaja o libertad que tenía, desaparece para su titular. Si tuviéramos por propiedad cada aspecto de esa autonomía, privilegio, ventaja o libertad, la regla constitucional que permite limitar la propiedad equivaldría a letra muerta, lo que se contradiría con múltiples fallos de este Tribunal que han tolerado, en determinados casos y bajo ciertas condiciones, la regulación de la propiedad (...) Por el contrario, legitimar cualquiera regulación o limitación, sin considerar su impacto sobre la propiedad, desnaturalizaría la protección de este derecho fundamental ("la limitación tiene sus límites (...)”128.

En este sentido, y finalizando su raciocinio en este considerando para el TC el "carácter esencial de lo que se priva en virtud de la regulación es un parámetro siempre útil para hacer la distinción y debe utilizarse aunque se determine que, prima facie, se trata de una regulación" ${ }^{129}$.

Aplicando estos conceptos, procede a señalar que, en la especie, lo que hace la norma en cuestión es regular, no privar, pues si bien altera el precio, la empresa puede seguir usando, gozando y disponiendo del uso ${ }^{130}$. La cuestión pasa a ser entonces para el TC si la alteración del precio del contrato, habiendo tenido un fin regulatorio, "es de tal

nar las reglas a que debe ajustarse el ejercicio del dominio, estableciendo un modo limitado y menos libre de ejercer la propiedad sobre la cosa. Así, habrá casos claros de privación (como cuando se le quita a una persona todo el bien sobre el que recae el dominio) y otros casos claros de regulación (como aquellos en que los actos propios del dominio que se limitan son irrelevantes)". Sentencia del Tribunal Constitucional Rol No 505 (2007) c. 22.

126 Sentencia del Tribunal Constitucional Rol No 505 (2007) c. 22.

127 Sentencia del Tribunal Constitucional Rol No 334 (2001) c. 20 y 21.

128 Sentencia del Tribunal Constitucional Rol No 505 (2007) c. 23.

129 Sentencia del Tribunal Constitucional Rol No 505 (2007) c. 23.

130 Sentencia del Tribunal Constitucional Rol No 505 (2007) c. 24. 
naturaleza y magnitud que priva a su titular de su propiedad o de alguno de sus atributos esenciales" 131 .

En este sentido, la primera pregunta que el TC busca resolver, consiste en si cualquiera alteración en el precio por usar un bien, independiente de su magnitud, priva a la requirente de uno de los atributos esenciales del dominio. Para el TC "el precio es, a no dudarlo, un elemento esencial en un contrato que regula el uso que una parte puede hacer de las instalaciones y fija el precio o peaje que habrá de pagar por ese uso, como el que vinculó a las partes" 132 , sin embargo, prosigue,

"eso no debe confundirse con que una alteración de ese precio, por la vía legislativa, independiente de su magnitud, prive a la requirente de la esencia de su derecho de propiedad o de alguno de sus atributos o facultades esenciales (...) Su propiedad no queda desprovista de lo que es consustancial no resulta irreconocible o impedida de ejercicio o privada de tutela conforme ha entendido tradicionalmente este Tribunal la esencia de un derecho"133.

Con todo, para el TC el que una alteración cualquiera del precio no implique privación de la propiedad no equivale a afirmar que cualquiera alteración en el precio no pueda serlo. En efecto,

"si la magnitud de la alteración fuese de tal naturaleza que impidiera la razón de ser del contrato, entonces la titular podría efectivamente sostener que se le ha privado de propiedad. Desde un punto de vista objetivo, la razón de ser de un contrato es su utilidad económica. La razón por la cual se contrata en los mercados es el lucro. Si la regulación estatal sobre un precio privara a una parte de lucrar, entonces esa parte podría sostener que se le ha privado de la esencia de su propiedad, pues en ella ha desaparecido su esencia o razón de ser, uno de sus atributos esenciales, como es legítima expectativa de beneficio o lucro" ${ }^{134}$.

Para el TC, sin embargo, el privado no puede impedir que una necesidad pública modifique la cuantía del lucro que venía percibiendo en virtud del contrato, si es que el legislador justifica esa limitación en una exigencia de interés público constitucionalmente aceptado ${ }^{135}$. Más aún, dicho Tribunal sostiene que en la especie no se alegó tal privación -la obtención de lucro- y más aún se ha seguido funcionando e invirtiendo en dicha actividad por lo que no podría suponerse tal efecto.

Finalmente, para el TC la regulación en cuestión se encuentra perfectamente legitimada por cuanto cumple con los requisitos del artículo 19 no 24 CPR pues fue

\footnotetext{
131 Sentencia del Tribunal Constitucional Rol No 505 (2007) c. 24.

132 Sentencia del Tribunal Constitucional Rol No 505 (2007) c. 25.

133 Sentencia del Tribunal Constitucional Rol No 505 (2007) c. 25.

134 Sentencia del Tribunal Constitucional Rol No 505 (2007) c. 26.

135 Sentencia del Tribunal Constitucional Rol No 505 (2007) c. 26.
} 
establecida por ley y consta de las actas de su discusión los motivos de utilidad pública que la motivaron ${ }^{136}$. Ello lleva a rechazar la inaplicabilidad deducida.

La disidencia por su parte, compuesta por los ministros Bertelsen, Vodanovic y Venegas, quienes estuvieron por acoger el requerimiento, construye su argumentación sobre la base de que, en primer lugar, "la privación de la propiedad puede ser total (sobre todo el bien) o parcial (sobre alguno de los atributos o facultades esenciales del dominio)"137; en segundo lugar, que "la naturaleza de la privación no se determina por la cuantía (mucho o poco), sino que hay privación en la supresión de cualquier atributo o facultad esencial del dominio"138; en tercer lugar, que el precepto legal observado, al aplicarse a la situación jurídica que genera la causa judicial, implica quitar al titular la propiedad que tiene sobre el bien incorporal en que recae "y, desde luego, lo priva de los atributos y facultades esenciales del dominio y, en general, de obtener la utilidad económica que -por su naturaleza- proporciona el bien" ${ }^{139}$.

De lo anterior concluyen que no puede sostenerse que no hay privación por cuanto al titular le quedan otros derechos emanados del contrato, pues si bien de la convención emanan diversos derechos y obligaciones (de fisionomía propia cada uno), hay sobre cada uno de ellos derecho de propiedad. En la especie se ha privado de la propiedad sobre el derecho al precio convenido. Además al estar la esencia del dominio radicada en la utilidad económica de la cosa, en el caso propuesto ella ha sido afectada sustancialmente ${ }^{140}$.

\subsection{EVALUACiÓN}

¿Cuánto de la experiencia de la jurisprudencia norteamericana sobre expropiación regulatoria está presente en los fallos del TC analizados? ¿Con qué calidad son contestadas las preguntas relativas a la magnitud de la limitación legal y la consideración de los criterios económicos?

En primer lugar, y desde la perspectiva de las sentencias 505 y 506, se utiliza un criterio parecido al del juez Holmes en Penn Coal, esto es que mientras la propiedad puede ser regulada o limitada (en Chile cumpliendo primero los requisitos del artículo 19 No 24), si esta va demasiado lejos será reconocida como una expropiación (considerandos $22^{\circ}, 23^{\circ}, 24^{\circ}$ y $26^{\circ}$ ). Con todo, el reconocimiento en el considerando $22^{\circ}$ de esta sentencia de que el análisis se encuadra en lo que en "el derecho comparado ha denominado desde hace casi un siglo 'regulaciones expropiatorias" 141 , no es sinónimo de que se ha revisado con exhaustividad los diferentes tests que se han desarrollado en el derecho comparado, y en particular en el derecho norteamericano.

Un contra argumento a lo anterior, dice relación con que el Tribunal, en el considerando $26^{\circ}$, sofistica el análisis, y vincula la intensidad y magnitud de la regula-

\footnotetext{
136 Sentencia del Tribunal Constitucional Rol No 505 (2007) c. 28 a 34.

137 Sentencia del Tribunal Constitucional Rol No 505 (2007) c. 5.

138 Sentencia del Tribunal Constitucional Rol No 505 (2007) c. 6.

139 Sentencia del Tribunal Constitucional Rol No 505 (2007) c. 9.

140 Sentencia del Tribunal Constitucional Rol No 505 (2007) c. 10 al 12.

141 Sentencia del Tribunal Constitucional Rol No 505 (2007) c. 22.
} 
ción, con la extensión de la interferencia en relación a su "legítima expectativa de beneficio económico o lucro" ${ }^{142}$. Este criterio podría vincularse al de la regla central creada en el test Penn Central, esto es, la extensión de la interferencia en relación a las expectativas económicas razonables de la inversión del particular.

El si se siguió o no los precedentes -o parte de ellos- de Penn Coal y Penn Central es discutible. A favor está la formación anglosajona del Ministro redactor (Jorge Correa en Yale). En contra está el hecho de que el lenguaje acerca de la "utilidad económica" se vincula al familiar contexto del derecho de contratos: "la razón de ser de un contrato es su utilidad económica"143.

Por otra parte, al analizarse la posición disidente, llama la atención, en primer lugar, el que pareciera hacerse cargo del debate originado en Penn Central en atención a cómo debe considerarse la propiedad -en términos de unidad- para determinar si hay o no expropiación. En efecto, en Penn Central la Corte estimó que la unidad de propiedad a ser escrutada era la totalidad de ella (se le privaba del beneficio económico de su espacio aéreo, pero permanecía todo el resto), lo que fue muy criticado y revertido, como sabemos, en el fallo Lucas.

La disidencia plantea también esto señalando que no basta con que le queden al particular otros usos y derechos a salvo, sino que mientras que se le prive de uno de ellos habrá expropiación, como lo es en el caso el dominio sobre el derecho al precio establecido. Ello implica establecer un criterio más objetivo, sin hacer hincapié en la magnitud de la interferencia como lo hace la sentencia.

Para Romero, no es clara la diferencia entre la sentencia y el voto de minoría ${ }^{144}$. Coincidimos con el autor, en tal vez la cuestión crucial que quedó sin resolverse y de la esencia del test de la expropiación regulatoria, en el sentido de que "el fallo parece bien orientado, pero en él no se entra a un análisis concreto de cuál fue la magnitud de la pérdida de utilidad o beneficio económico o lucro" ${ }^{145}$, sin perjuicio de que no queda claro si los demandantes detallaron cuál habría sido el efecto pecuniario de la regulación legal que impugnaron. Así, "se habla de la importancia de la magnitud de la pérdida sufrida por la limitación legal, luego se sugiere su razonabilidad, pero del fallo no se desprende fundamento empírico alguno para tal aseveración"146.

\footnotetext{
142 Sentencia del Tribunal Constitucional Rol No 505 (2007) c. 26.

143 Sentencia del Tribunal Constitucional Rol No 505 (2007) c. 26.

144 Para el autor: “(...) podría sugerirse que el tipo de argumentación entre este voto y la opinión de la mayoría del TC que terminó predominando no es tan disímil. Ambos de una u otra forma aceptan que una regulación o limitación pueda llegar a ser una privación o expropiación. Ambos aceptan tácitamente la teoría del continuo conceptual, aunque en el voto de minoría las limitaciones y obligaciones legales a la propiedad parecen tener un carácter y número más acotado”. ROMERO (2008) p. 45.

145 ROMERO (2008) p. 44.

146 Romero (2008) p. 44. En efecto, "en la apreciación empírica del monto de la pérdida económica que la regulación ha implicado para el afectado (ejercicio ausente en este fallo) se debe dirimir qué porcentaje de pérdida es tolerable o admisible y cuál no, así como la determinación del ámbito (mayor o menor) sobre el cual debe estimarse la pérdida. Cuando se habla de la magnitud del daño debe intentar señalarse la fracción relevante. Es decir, por un lado el daño (o para estos efectos, pérdida de ventaja patrimonial o utilidad económica producto de la intervención reguladora) y por el otro la porción, parcela o ámbito sobre el cual recae la pérdida. Como en toda fracción, se puede hablar de un numerador y un denomina-
} 
Finalmente, podemos señalar que si algo ha quedado claro en esta revisión acerca de la evolución de la jurisprudencia sobre expropiación regulatoria en Estados Unidos es el serio esfuerzo que la Corte Suprema de ese país ha intentado hacer para tratar de abordar un tema de suyo complejo, aunque observamos que estos estándares no son ni claros ni evidentes. Ello se enmarca, y como sostiene la Corte en Lingle, en un escenario en que los tribunales en general y la Corte Suprema en particular, enfrentan un problema de capacidad institucional a la hora de efectuar su labor de revisión judicial sobre estas regulaciones ${ }^{147}$.

En este sentido, si algo podemos aprender de la jurisprudencia norteamericana es la habilidad que ha tenido para detectar ciertas cuestiones o indicadores, que de alguna manera, activan las "alarmas" de la revisión judicial frente a regulaciones "sospechosas" desde la perspectiva de atentar contra el derecho de propiedad y la igualdad ante las cargas públicas. Entre ellas destacan, el uso del poder de policía para evadir la cláusula de expropiación (uso público, justa compensación y debido proceso); cómo una determinada regla de la Corte puede afectar la distribución de derechos anteriores a la medida estatal que se está evaluando como expropiatoria -particularmente en el caso en que existían contratos entre las partes-; y, bajo qué contextos incide la cuestión de la compensación, sobre todo porque hay cierta coincidencia doctrinaria que aconseja, por motivos de eficiencia el que no procedan compensaciones -y ello debiera llevar a la Corte a jugarse por sancionar una restricción como regulación y no como expropiaciónen caso de actividades privadas que generen externalidades negativas, y en donde la restricción operaría como mecanismo de internalización de la misma.

En efecto, la jurisprudencia en esta materia no solo ha sido tratada desde el derecho constitucional, sino el derecho regulatorio norteamericano por el impacto que ha tenido desde la perspectiva de la asignación eficiente de los recursos.

Lueck y Miceli se muestran relativamente conformes con el desarrollo jurisprudencial en este ámbito en relación a la teoría económica. Para los autores el balance (trade-off) que debe realizarse consiste en ser eficientes en el uso de la propiedad, por un lado, y las decisiones regulatorias, por el otro. La manera de alcanzar un equilibrio eficiente se encuentra en establecer una regla de compensación que sea cero (0) si el valor de la pérdida del propietario es menor que las ganancias de la regulación; y, procede una compensación completa si el gobierno sobrerregula, esto es, si la pérdida del propietario es mayor que la ganancia de la regulación ${ }^{148}$.

Para los autores esta mirada de eficiencia va de la mano con los tests que han sido desarrollados por la Corte Suprema, lo que permite diversas ganancias desde la perspectiva doctrinaria. Primero, permite interpretar los "usos nocivos" como aquellas actividades que son reguladas de manera eficiente, no procediendo compensación. Ello se produce cuando

dor. Si ha de tomarse en consideración la magnitud de la limitación, debe atenderse a lo limitado, expropiado o perdido en relación a algo. Ese "algo", en este caso particular, puede ser, por ejemplo, el negocio integral de cada recurrente (Eléctricas Panguipulli y Puyehue), el negocio o transacción particular con Transelec, o incluso, algún aspecto parcial de dicho negocio o transacción”. ROMERO (2008) p. 47.

147 Ver STONE et al. (2005) p. 1039.

${ }^{148}$ LUECK y MiCELI (2007) p. 243. 
las pérdidas del propietario son menores a las ganancias obtenidas con la regulación. Segundo, provee un estándar económico para definir cuándo una regulación llega "demasiado lejos" bajo el test de "disminución del valor", y ello ocurre cuando la regulación ha sido promulgada de manera ineficiente, esto es, cuando las pérdidas del propietario son mayores que las ganancias de la regulación. Finalmente, establece un estándar que es económicamente equivalente a la definición que hace el derecho común de actividades molestas (una actividad prohibida eficientemente), por lo que es consistente con el umbral de compensación implícito en la excepción de daño (nuisance exception) ${ }^{149}$.

Para Fischel, Holmes detectó bien en Penn Coal los incentivos naturales que posee el regulador en materia de expropiación regulatoria: "Si la propiedad puede ser adquirida a través de regulaciones en el ejercicio del poder de policía, las cuales no requieren de compensación, entonces la legislatura es apta para expandir el ámbito del poder de policía para evadir los gastos de adquirirla a través del dominio eminente" ${ }^{150}$.

En otras palabras, el regulador tiene todos los incentivos (no tan solo económicos en el sentido de costos, sino también político-institucionales al aumentar su poder) para intentar evadir el estatuto constitucional de expropiación que le establece una camisa de fuerza robusta para impedir que expropie excesivamente. De alguna manera el requisito de uso público, justa compensación y debido proceso pasan a ser los "precios" que paga el Estado al expropiar y eso lo obliga a realizar un pormenorizado balance costo-beneficio respecto de si vale o no la pena llevar a cabo una determinada acción.

\section{CONCLUSIÓN}

El presente trabajo ha buscado responder la pregunta en torno a cómo fortalecer la revisión judicial de la regulación económica, desde una perspectiva metodológica, esto es, propugnando la tesis de que existen ciertos tests constitucionales -de amplia utilización en el derecho comparado- cuya estructura los hace particularmente idóneos para escrutar las regulaciones económicas y ponderar su impacto en términos del costo en derechos fundamentales que generan. Si bien se ha estimado que el TC va en la dirección correcta a través del uso que ha hecho del principio de proporcionalidad y de la expropiación regulatoria, es posible avanzar en la sofisticación de ambos si se miran la experiencia en el derecho comparado, en particular, el desarrollo jurisprudencial de la proporcionalidad por parte del TC español y el de la expropiación regulatoria por parte de la Corte Suprema norteamericana. Todo ello, en un contexto en que el "nuevo" requerimiento de inaplicabilidad (posterior a la reforma constitucional de 2005), presenta una oportunidad única para permitir el mayor desarrollo de estos y otros tests. La idea misma de test apunta a que la metodología utilizada -el tipo de preguntas, elementos fácticos, consideraciones de los expertos- es esencial para arribar al mejor resultado entre los posibles, aquel que maximiza de la mejor manera el mandato constitucional, que es, al final del día, el objetivo último de la revisión judicial.

149 LUECK y MiCELI (2007) p. 244.

${ }^{150}$ FISCHEL (1995) p. 20. 


\section{BIBLIOGRAFÍA CITADA}

AlEXY, Robert (2002): “Epílogo a la teoría de los derechos fundamentales", Revista Española de Derecho Constitucional, N o 66: pp. 13-64.

Aldunate Lizana, Eduardo (2008): Derechos fundamentales (Santiago, Legal Publishing) $439 \mathrm{pp}$.

AldunATE LizANA, Eduardo (2006): "Limitación y expropiación: Scilla y Caribdis de la dogmática constitucional de la propiedad”, Revista Chilena de Derecho, vol. 32 No 2: pp. 285-303.

AleinikOfF, Alexander (1987): "Constitutional Law in the Age of Balancing", Yale Law Journal, vol. 96: pp. 943-1008.

AmAR, Akhil R. (1998): The Bill of Rigthts (New Haven, Yale University Press) 412 pp.

Amar, Akhil R. (2006): America's Constitution. A biography (New York, Randon House) $655 \mathrm{pp}$.

BARNES, Javier (1994): "Introducción al principio de proporcionalidad en el derecho comparado y comunitario", Revista de Administración Pública, No 135: pp.495-522.

BARNES, Javier (1998): "El principio de proporcionalidad. Estudio preliminar", Cuadernos de Derecho Público, Vol. 5: pp. 15-49

BEST, Robert K. (2001): "Regulatory Takings: A Brief History", Working Paper ALIABA Course of Study: Inverse Condemnation and Related Government Liability. Disponible en: http://papers.ssrn.com/sol3/papers.cfm?abstract_id=701322 [fecha de consulta: 23 de julio de 2010]

Boettiger Philipps, Camila (2009): "Regulación del Estado con fines sociales en materia urbanística: ¿limitación a la propiedad, impuestos o cargas públicas?”, Jornadas de Derecho Público 2007, Pontificia Universidad Católica de Valparaíso: pp. 121-136.

ClÉRICO, Laura (2009): El examen de proporcionalidad en el derecho constitucional (Buenos Aires, Editorial Universitaria de Buenos Aires) 409 pp.

CORDERO QUINZACARA, Eduardo (2006): "La dogmática constitucional de la propiedad en el derecho chileno", Revista de Derecho Valdivia, vol. XIX No 1: pp. 125-148.

Cordero Quinzacara, Eduardo (2008) "De la propiedad a las propiedades. La evolución de la concepción liberal de la propiedad”, Revista de Derecho Universidad Católica de Valparaiso, No XXXI: pp. 493-525.

Couso Salas, Javier (2002): "La Producción del Derecho Económico Internacional y la Necesidad de una Democracia Cosmopolita". Working Paper del Seminario Sela (Yale). Disponible en: http://islandia.law.yale.edu/sela/cousos.pdf [fecha de consulta: 23 de julio de 2010]

DelaVEAU SweTT, Rodrigo (2006) "La Regulación Expropiatoria en la Jurisprudencia Norteamericana”, Revista Chilena de Derecho, vol. 33 No 3: pp. 411-438.

Draeger, Tonya R. (2006): "Property as a Fundamental Right in the United States and Germany: A Comparison of Takings Jurisprudence", Transnational Law Journal, vol. 14: pp. 363-400.

Engel, Christoph (2001): “Gemeinschaftsgüter: Recht, Politik und Ökonomie", Preprints aus der Max-Planck-Projektgruppe Recht der Gemeinschaftsgüter (Bonn, Max 
Planck Institute for Research on Collective Goods). Disponible en: http:// papers.ssrn.com/sol3/papers.cfm?abstract_id=296367 [fecha de consulta: 23 de julio de 2010]

FALLON, JR., Richard (2007): “Strict Judicial Scrutiny”, UCLA La Review, vol.54 pp: 1267-1345.

FERMANDois VÖHRINGER, Arturo (2006): Derecho constitucional económico (Santiago, Ediciones Universidad Católica de Chile) volumen I. 333 pp.

FERMANDOIS VÖHRINGER, Arturo (2008): "Inaplicabilidad y control concreto del Tribunal Constitucional: enjuiciando la arbitrariedad en la aplicación de la ley", Actualidad Jurídica Universidad del Desarrollo, No 17: pp. 175-194.

FERnÁNDEZ NieTO, Josefa (2008): Principio de proporcionalidad y derechos fundamentales: una perspectiva desde el derecho público común europeo (Madrid, Editorial Dykinson) $681 \mathrm{pp}$.

FisCHEL, William A. (1995): Regulatory Takings: Law, Economics and Politics (Massachussets, Harvard University Press) 415 pp.

GARCÍA GARCÍA, José Francisco (2009): "Corte suprema y gobierno judicial: un programa de reformas”, Actualidad Jurídica Universidad del Desarrollo, vol. 20, No1: pp. 81121.

García García, José Francisco y Verdugo Ramírez, Sergio (2010, en prensa): “Tribunal Constitucional, certiorari y precedente", II Jornadas de constitucionalistas jóvenes (U. Católica del Norte-Coquimbo).

GRAFTON, John (ed.) (2000): The Declaration of Independence and other great documents of American History 1775-1865 (Nueva York, Dover) 96 pp.

Hart Ely, John (1980): Democracy and Distrust. A Theory of Judicial Review, (Massachusetts, Harvard University Press) 283 p.

KLUTH, Winfried (1998): "Prohibición de exceso y principio de proporcionalidad en el Derecho Alemán”, Cuadernos de Derecho Público, vol. 5: pp. 219-237.

LueCK, Dean y Thomas MiCEli (2007): "Property Law" en Shavell, Steven y A. Mitche11 Polinsky (eds.): Handbook of Law and Economics, Vol. 1 (New York, North-Holland) $826 \mathrm{pp}$.

MARTín VidA, María Angeles (2003) "Evolución del principio de igualdad en Estados Unidos”, Revista Española de Derecho Constitucional, vol. 68: pp. 151-194.

MiCELI, Thomas y Kathleen SEgERSON (1999): "Takings", The Encyclopedia of Law and Economics on line, paper No 6200. Disponible en: http://encyclo.findlaw.com/ 6200book.pdf [fecha de consulta: 23 de julio de 2010]

MoHor AbUAUAD, Salvador (1989): “Taxonomía de las limitaciones al dominio y derecho de indemnización”, Revista Chilena de Derecho, vol. 16 No 2: pp. 283-308.

MontT Oyarzún, Santiago (2005): "Aplicación de los Tratados Bilaterales de Protección de Inversiones por tribunales chilenos. Responsabilidad del Estado y expropiaciones regulatorias en un mundo crecientemente globalizado", Revista Chilena de Derecho, vol. 32, $\mathrm{N}^{\circ}$ 1: pp. 19-78.

Nogueira Alcalá, Humberto (1997): Dogmática constitucional (Talca, Editorial Universidad de Talca) $380 \mathrm{pp}$. 
Nogueira AlCAlÁ, Humberto (2006): Lineamientos de interpretación constitucional y del bloque constitucional de derechos (Santiago, Librotecnia) 413 pp.

Nogueira Alcalá, Humberto (2005): "El control represivo concreto y abstracto de inconstitucionalidad de leyes en la reforma constitucional 2005 de las competencias del Tribunal Constitucional y los efectos de sus sentencias”, en Nogueira AlCalá, Humberto (coordinador) La Constitución Reformada de 2005, Centro de Estudios Constitucionales de la Universidad de Talca. Editorial Librotecnia, pp. 421-456.

Perello Domenech, Isabel (1997): "El principio de proporcionalidad y la jurisprudencia constitucional”, Jueces para la Democracia, No 28: pp. 69-75.

Rajevic Mosler, Enrique Petar (1996): "Limitaciones, reserva legal y contenido esencial de la propiedad privada", Revista Chilena de Derecho, vol. 23 No 1: pp. 23-97.

Rajevic Mosler, Enrique Petar (1998): "La propiedad privada y los derechos adquiridos ante la planificación urbana”, Revista Chilena de Derecho, vol. 25 No 1: pp. 65112.

Real Academia Española (2005): Diccionario de la Real Academia de la Lengua Española (22a Edición, Buenos Aires, Grafinor S.A.) Tomo II.

Romero GuZmán, Juan José (2008): “¿Capturados por nuestra suspicacia? Algunas aproximaciones acerca del origen, desarrollo y extinción de las regulaciones”, Revista Chilena de Derecho, vol. 35, No1: pp. 9-35.

SAONA MARÍn, Tamara (2009): "Aplicación del principio de proporcionalidad en sentido amplio en el control constitucional a posteriori de normas penales por el tribunal constitucional chileno". Disponible en: http://congresoconstitucional.cl/upload/69/ Tamara\%20Soana_1252889443.pdf [Fecha de consulta: 8 de enero de 2010].

SARMIENTO RAMíREZ-ESCUDERO, Daniel (2003): "El control de la proporcionalidad en la actividad administrativa", Revista de Administración Pública, No 162: pp. 145-171.

SIEGAN, Bernard H. (1980): Economic Liberties and the Constitution (Chicago, The University of Chicago Press) 355 pp.

SiEgEL, Stephen A. (2006): "Origin of the Compelling State Interest Test and Strict Scrutiny”, American Journal of Legal History, vol. 48: pp. 355-389.

Stone, Geoffrey R., Louis Michael Seidman, Cass R. Sunstein, Mark V. Tushnet y Pamela S. Karlan (2005): Constitutional Law (New York, Aspen) 1704 pp.

Sullivan, Kathleen M. (1993): "Foreword: The Justices of Rules and Standards", Harvard Law Review, vol. 106: pp. 22-123.

SweET, Alec S. y Jud MATHEWS (2008): "Proportionality Balancing and Global Constitutionalism”, Columbia Journal of Transnational Law, vol. 47: pp. 73-165.

SweET, Alec S. y Jud Mathews (2010): "All things in Proportion? American Rights Doctrine and the Problem of Balancing", Yale Law School Faculty Scholarship Series, paper No. 30. 89 pp. Disponible en: http://digitalcommons.law.yale.edu/cgi/ viewcontent.cgi? article $=1029 \&$ context $=$ fss_papers [Fecha de consulta: 8 de octubre de 2010].

UGARTE GODOY, José Joaquín (2001): “Limitaciones al dominio, de las meras restricciones y de cuándo dan lugar a indemnización”, Revista Chilena de Derecho, vol. 28 No 2: pp. 425-448. 
Zapata Larraín, Patricio (2008): Justicia constitucional (Santiago, Editorial Jurídica de Chile), 623 pp.

ZÚNIIGA URBINA, Francisco (2005): “Control concreto de constitucionalidad: recurso de inaplicabilidad y cuestión de constitucionalidad en la reforma constitucional”, en Nogueira AlCalá, Humberto (coordinador): La Constitución Reformada de 2005. (Santiago, Editorial Librotecnia) pp. 473-494.

\section{JURISPRUDENCIA CITADA}

\section{CORTE SUPREMA, ESTADOS UNIDOS}

Agins v. City of Tiburon, 447 US 255 (1980).

Armstrong v. United States, 364 US 40 (1960).

Babbitt v. Youpee, 519 US 234 (1997).

Brown v. Legal Foundation of Washington, 538 US 216 (2003).

First English Evangelical Church v. County of Los Angeles, 482 US 304 (1987).

Griggs v. County of Allegheny, 369 US 84 (1962).

Goldblatt v. Hempsted, 369 US 590 (1962).

Hadacheck v. Sebastian, 239 US 394 (1915).

Hodel v. Irving, 481 US 704 (1987).

Keystone Bituminuos Coal Association v. DeBenedictis, 480 US 470 (1987).

Lingle v. Chevron U.S.A. INC., 544 US 528 (2005).

Loretto $v$. Teleprompter Manhattan, 458 US 419 (1982).

Lucas v. South Carolina Coastal Council, 505 US 1003 (1992).

Miller v. Schoene, 276 US 272 (1928).

Mugler $v$. Kansas, 123 US 623 (1887).

Nectow v. Cambridge, 272 US 365 (1926).

Nollan v. California Coastal Commission, 483 US 825 (1987).

Palazollo v. Rhode Island, 533 US 606 (2001).

Pennsylvania Central Transportation Co. v. City of New York, 438 US 104 (1978).

Pennsylvania Coal Co. v. Mahon, 260 US 393 (1922).

Reinman v. Little Rock, 237 US 171 (1915).

Tahoe-Sierra Preservation Council v. Tahoe Regional Planning Agency, 535 US 302 (2002).

United States v. Causby, 328 US 256 (1946).

United States v. Fuller, 409 US 488 (1973).

TribunAL CONSTITUCIONAL, EsPAÑA

Sentencia Tribunal Constitucional Español 62/1982.

Sentencia Tribunal Constitucional Español 66/1985.

Sentencia Tribunal Constitucional Español 55/1996.

Sentencia Tribunal Constitucional Español 161/1997.

Sentencia Tribunal Constitucional Español 49/1999.

Sentencia Tribunal Constitucional Español 98/2000.

Sentencia Tribunal Constitucional Español 186/2000. 


\section{Tribunal Constitucional, Chile}

Sentencia del Tribunal Constitucional Rol No 28, 8 de abril de 1985.

Sentencia del Tribunal Constitucional Rol No 53, 5 de abril de 1988.

Sentencia del Tribunal Constitucional Rol No 226, 30 de octubre de 1995.

Sentencia del Tribunal Constitucional Rol No 245, 2 de diciembre de 1996.

Sentencia del Tribunal Constitucional Rol No 246, 2 de diciembre de 1996.

Sentencia del Tribunal Constitucional Rol No 253, 15 de abril de 1997.

Sentencia del Tribunal Constitucional Rol No 280, 20 de octubre de 1998.

Sentencia del Tribunal Constitucional Rol No 325, 22 de enero de 2001.

Sentencia del Tribunal Constitucional Rol No 334, 21 de agosto de 2001.

Sentencia del Tribunal Constitucional Rol No 505, 6 de marzo de 2007.

Sentencia del Tribunal Constitucional Rol No 506, 6 de marzo de 2007.

Sentencia del Tribunal Constitucional Rol No 519, 5 de junio de 2007.

Sentencia del Tribunal Constitucional Rol No 541, 26 de diciembre de 2006.

Sentencia del Tribunal Constitucional Rol No 755, 31 de marzo de 2008.

Sentencia del Tribunal Constitucional Rol No 790, 11 de diciembre de 2007.

Sentencia del Tribunal Constitucional Rol No 797, 24 de enero de 2008.

Sentencia del Tribunal Constitucional Rol No 1141, 17 de marzo de 2009.

Sentencia del Tribunal Constitucional Rol No 1204, 28 de mayo de 2009.

Sentencia del Tribunal Constitucional Rol No 1215, 30 de abril de 2009.

Sentencia del Tribunal Constitucional Rol No 1234, 7 de julio de 2009.

Sentencia del Tribunal Constitucional Rol No 1295, 6 de octubre de 2009.

Sentencia del Tribunal Constitucional Rol No 1340, 29 de septiembre de 2009.

Sentencia del Tribunal Constitucional Rol No 1345, 25 de mayo de 2009. 